\title{
Evaluation of The Production of Second Generation Ethanol by Co-Culture of Saccharomyces Cerevisiae and Pachysolen Tannophilus Immobilized in Sodium Alginate.
}

Marcello Lima Bertuci ( $\sim$ marcellobertuci@gmail.com )

UNESP: Universidade Estadual Paulista Julio de Mesquita Filho https://orcid.org/0000-0002-9493-

3578

Mariane Daniella da Silva

UNESP: Universidade Estadual Paulista Julio de Mesquita Filho João Pedro Cano

UNESP: Universidade Estadual Paulista Julio de Mesquita Filho

Crispin Humberto Garcia Cruz

UNESP: Universidade Estadual Paulista Julio de Mesquita Filho

\section{Research Article}

Keywords: Agroindustrial waste, Bioethanol, Consortium, Rice husk, Acid Hydrolysis

Posted Date: June 14th, 2021

DOI: https://doi.org/10.21203/rs.3.rs-525446/v1

License: (c) (i) This work is licensed under a Creative Commons Attribution 4.0 International License.

Read Full License 


\title{
Evaluation of the production of second generation ethanol by co-culture of Sacharomyces cerevisiae and Pachysolen tannophilus immobilized in sodium alginate
}

\author{
Marcello Lima Bertuci ${ }^{1}$, Mariane Daniella da Silva ${ }^{1}$, João Pedro Cano ${ }^{1}$, Crispin Humberto Garcia Cruz ${ }^{1}$

\begin{abstract}
The production of an alternative form of fuel that replaces fossil fuels has been increasingly studied due to the environmental impacts generated by its excessive use, as well as the depletion of these fossil energy sources. Ethanol obtained from the crushing of sugar cane has been used as a substitute for these fuels, mainly in the automotive area. However, alternative sources are being studied to produce the so called second generation bioethanol. This would avoid competition for food producing agricultural areas and agroindustrial waste is a great source for obtaining it. In general, these residues are not always completely reused and are disposed of inappropriately in the environment, becoming contaminants. Therefore, the use of agroindustrial waste can become a renewable source of energy, in addition to reducing environmental impacts. The objective of this work is to produce second generation bioethanol as an alternative to the one currently used, using the rice husk hydrolyzate by the consortium formed by Saccharomyces cerevisiae and Pachysolen tannophilus. For this, an acid hydrolysis was performed with $2 \%$ sulfuric acid during 10 minutes of heating in an autoclave, after which the hydrolyzate was detoxified with the use of activated carbon. The crude and detoxified hydrolysates were used as a substrate for the fermentation medium with an initial concentration of $50 \mathrm{mg} / \mathrm{mL}$ of reducing sugars. The fermentation process with the use of both yeasts in the crude hydrolyzate medium, in the detoxified medium and in a synthetic medium composed of glucose, was carried out for $24 \mathrm{~h}, 30^{\circ} \mathrm{C}, 0 \mathrm{rpm}$ and $\mathrm{pH}$ 6.5.The best results for the ethanol production of Saccharomyces cerevisiae was the synthetic medium with $20.6 \mathrm{mg} / \mathrm{mL}$. For the yeast Pachysolen tannophilus, its highest production was in a synthetic medium with $11.67 \mathrm{mg} / \mathrm{mL}$. The intercropping of the two yeasts proved to be efficient with a greater ethanol production reaching $21.5 \mathrm{mg} / \mathrm{mL}$, the hydrolyzed and detoxified media showed great potential for ethanol production both in intercropping and in monoculture.
\end{abstract}

Keywords: Agroindustrial waste; Bioethanol; Consortium; Rice husk; Acid Hydrolysis;

Marcello Lima Bertuci

marcellobertuci@gmail.com

${ }^{1}$ São Paulo State University (UNESP), Institute of Biosciences, Humanities and Exact Sciences, Departament of Food Engineering and Technology, Cristóvão Colombo Street 2265, 15054-000. São José do Rio Preto, São Paulo, Brazil. 


\section{Introduction}

The concern to reduce the emission of gases related to the greenhouse effect, mainly derived from automobiles, has motivated the search for substitutes for fossil fuels that cause less environmental impact. Because of this, obtaining biofuels from alternative sources has become a major focus of study. Thus, they are an alternative to reduce the use of petroleum-derived fuels, whose supply and price depend on the moods of the producing countries, in addition to generating various environmental damages. (1)(2)

Biofuels are fuels produced from organic matter. One of the most intresting and outstanding is the production of second generation ethanol, which is obtained from agro-industrial waste. Several countries consider the use of biomass for ethanol production, making it an alternative with the capacity to increase economic development, in addition to reducing the emission of greenhouse gases, having a reduction when compared to emissions caused by gasoline. (3)

The exploration of alternatives to increase the production of biofuels has become the focus of biotechnological development, due to the large amount of resources required for production, requiring, in addition to technological advances, management models that guarantee technical, economic and environmental aspects. (4)

Among the world agricultural production, Brazil has great prominence, due to its vast territory and its great agricultural production, this production generates a large amount of waste. Thus, presenting a great opportunity for generation and production of second generation bioethanol on a large scale in the national scenario. (5)

For the production of this bioethanol, which uses lignocellulosic biomass as a base, chemical (using acid and base), physical and biological (use of enzymes) processes can be used to break down the cellulose and hemicellulose present in the waste resulting in the release of sugars necessary to carry out the fermentative processes aimed at ethanol production (6). However, for the consumption of these hexoses and pentoses, a microorganism co-culture process is necessary, due to the fact that there is no microorganism that can consume these two fermentable sugars. Therefore, co-culture is a viable option that improves fermentation yield, generating greater ethanol production (7)

Saccharomyces cerevisiae is the most widely used yeast for fermentation processes due to its ability to consume hexoses and is generally used for ethanol production (8).

Pachysolen tannophilus was the first yeast recognized for its ability to consume pentoses, due to this ability it can consume the sugars from biomass, which were not consumed by S. cerevisiae in fermentation, without generating competition for the substrate. Thus, the relevance of co-culture benefits the process of obtaining ethanol. (9)

Cell immobilization is a process used to increase productivity in fermentation processes, separating cells from microorganisms in continuous and long-term processes. The fermentative process using immobilized microorganisms is more efficient to take advantage of the potential of yeasts for consumption of substrates and tolerance to the medium. This technique improves production and yield for obtaining ethanol (10).

Within this context, the objective of this work was to produce ethanol by individual cultures and coculture of Saccharomyces cerevisiae and Pachysolen tannophilus immobilized in sodium alginate, using rice husk acid hydrolyzate. 


\section{Materials and Methods}

The experimental part of the work was developed at the Biopolymers Laboratory of the Department of Food Engineering and Technology, Institute of Biosciences, Letters and Exact Sciences - IBILCE / UNESP, in São José do Rio Preto / SP.

\subsection{Industrial rice residue}

The rice husks were acquired from establishments that commercialize rice based products, situated at Municipal Dam of São José do Rio Preto, São Paulo, Brazil (Latitude: 2049'10.99" S and Longitude: $49^{\circ} 22^{\prime} 45.98^{\prime \prime} \mathrm{W}$ ).

\subsection{Processing of rice husks}

The industrial residue of rice consisting of husks was dried in an oven with air circulation, until it reached an approximate humidity of $12 \%$. Subsequently, the shells were ground to increase the contact surface and stored in plastic containers. The particle size was homogenized at $<0.64 \mathrm{~mm}$ using a Produtest brand atomizer.

\subsection{Rice husk chemical hydrolysis and detoxification}

The hydrolysis of rice husks took place in Erlenmeyer bottles of 250ml, at a scale of 10/100 (w/v) of rice husk in sulfuric acid $\left(\mathrm{H}_{2} \mathrm{SO}_{4}\right)$ with concentration $(2 \%)$. The bottles were submitted to heating in autoclave at $121{ }^{\circ} \mathrm{C} / 1.1 \mathrm{~atm}$. during $10 \mathrm{~min}$. Afterwards, the $\mathrm{pH}$ of the hydrolyzate material was neutralized (pH 7) with $\mathrm{NaOH}(50 \%)$ and filtered using Whatman $\mathrm{n}^{\circ} 1$ filter for the separation of residual solids, which were discarded. The obtained supernatant was used as substract for the production of ethanol by two methods: raw hydrolyzate $(\mathrm{RH})$, before being submitted into detoxification and detoxified raw hydrolyzate, that had already been through the detoxification stage with activated charcoal, for the removal of inhibitory agents from the microbial fermentation according to the methodology described by Mussatto; Roberto (11).

Before carrying out the fermentation process with the RH and DRH the total sugar values were measured by the phenol-sulfuric method (12) and reducing sugars total values by the copper-arsenate method (13) and (14). Also, the total phenolic compounds values were analyzed by the method described by FolinCiocalteau modified by Chaovanalikit; Wrolstad (15).

\subsection{Microorganism, maintenance, inoculum preparation and fermentation medium}

The samples of Saccharomyces cerevisiae ATCC 26602 yeast were kindly given by the Department of Chemistry Engineering of University of Coimbra - Portugal and Pachysolen tannophilus CCT 1891, acquired from the Collection of Tropical Cultures (CCT) of the André Tosello Foundation - Research and Technology of Campinas, SP. The yeasts was stored YM Medium composed by glucose $\left(10\right.$ g.L $\left.\mathrm{L}^{-1}\right)$, peptone $\left(5\right.$ g.L $\left.\mathrm{L}^{-1}\right)$, yeast extract $\left(3 \mathrm{~g} . \mathrm{L}^{-1}\right)$, malt extract $\left(3 \mathrm{~g} . \mathrm{L}^{-1}\right)$ and agar $\left(20 \mathrm{~g} . \mathrm{L}^{-1}\right)$ at pH 5.0, after being cultivated for $24 \mathrm{~h}$ a $30^{\circ} \mathrm{C}$. The microorganism strains were stored under freezing conditions $\left(4^{\circ} \mathrm{C}\right)$, while periodically being reactivated to maintain its viability. 
The inoculum was prepared by the addition of microorganisms previously cultivated in YM broth in Erlenmeyer bottles of $250 \mathrm{ml}$ containing $100 \mathrm{ml}$ of YM broth $(\mathrm{pH} 5.0)$. The inoculum was standardized by spectrophotometry with an absorbance of 0.6 and wave length of $600 \mathrm{~nm}$.

The production of ethanol was performed in culture media $(\mathrm{pH} 7)$ composed by yeast extract $\left(5 \mathrm{~g} . \mathrm{L}^{-1}\right)$; $\mathrm{KH}_{2} \mathrm{PO}_{4}\left(1 \mathrm{~g} . \mathrm{L}^{-1}\right) ; \mathrm{MgSO}_{4} .7 \mathrm{H}_{2} \mathrm{O}\left(1 \mathrm{~g} . \mathrm{L}^{-1}\right),(\mathrm{NH} 4)_{2} \mathrm{SO}_{4}\left(1 \mathrm{~g} . \mathrm{L}^{-1}\right)$ and a carbon supply (glucose, raw hydrolyzate or raw detoxified hydrolyzate).

\subsection{Cell immobilization - cell entrapment in alginate gel}

The cells of $S$. cerevisiae ATCC 26602 and P. tannophilus CCT 1891 under the conditions described in item 2.4 were added in a solution of sodium alginate $2.0 \%$ (Dynamic), previously prepared and sterilized, under agitation for 15 minutes. Afterwards, it was dripped (using a peristaltic pump) in a $3.0 \%$ calcium chloride solution (Sigma) under agitation, obtaining calcium alginate spheres containing the microorganism approximately $2.5 \mathrm{~mm}$ in diameter and weight of $0.06 \mathrm{~g}$; kept for 30 minutes under agitation, after this period, 3 $\mathrm{g}$ of these spheres were added in $125 \mathrm{ml}$ Erlenmeyers containing $50 \mathrm{ml}$ of the culture media used for the fermentation.

\subsection{Effect of culture medium on substrate (carbon source) consumption and ethanol biosynthesis by $S$.} cerevisiae and $P$. tannophilus

The culture media containing the crude hydrolyzate, the detoxified hydrolyzate and the synthetic medium with glucose was carried out in a D.B.O incubator without shaking $(0 \mathrm{rpm})$ and constant temperature of $30{ }^{\circ} \mathrm{C}$. The initial $\mathrm{pH}$ of the culture media was 6.5 , with the initial concentration of reducing sugars of $50 \mathrm{mg} /$ $\mathrm{mL}$.

The fermentation was evaluated using the monoculture of S. cererevisiae and P. tannophilus and by the co-culture of both yeasts, immobilized in sodium alginate spheres.

The fermentation occurred during $24 \mathrm{~h}$, where, samples were taken every $4 \mathrm{~h}$ at the phase-lag and at every $2 \mathrm{~h}$ at the phase-log for the purpose of evaluating the ethanol production, cellular biomass values, $\mathrm{pH}$ change, sugar values (reducing) and productivity calculation.

For analysis by the yeast consortium, it was performed with the inoculation of the yeast $S$. cerevisiae in the first $12 \mathrm{~h}$ of the fermentation, after, P. tannophilus was removed and inoculated.

\subsection{Analytical Methods}

The final $\mathrm{pH}$ values were determined in the fermentation broth using the potentiometer Digmed pHmeter model DM20.

The cellular concentration was determined by turbidimetry in spectrophotometer Biochrom, model Libra S22.

The ethanol concentration values were determined by gas chromatography (GC) in the fermented broth free of cells, using a GC Thermo Scientific Model Series Focus TR-WAX column HP-FFAP (25 m x 0.2 $\mathrm{mm} \times 0.3 \mu \mathrm{m}$ ) and flame ionization detector (FID). The oven temperature was kept at $70{ }^{\circ} \mathrm{C}$ (during the whole isothermal run), running time of $5 \mathrm{~min}$, the injector temperature was kept at $230^{\circ} \mathrm{C}$; detector temperature at 270 
${ }^{\circ} \mathrm{C}$ and injection of $200 \mu \mathrm{l}$ of sample vapor. The samples were left at a water bath of $40^{\circ} \mathrm{C}$ until reaching its point of equilibrium.

The values of total ethanol productivity, expressed in mass of the product formed per unit of time and per unit of volume (g.L-1.h-1), will be obtained through Equation 1.

$$
\mathrm{P}=\frac{(\mathrm{Pf}-\mathrm{Po})}{(\mathrm{tf}-\mathrm{to})} \quad \text { (Equation 1) }
$$

Where: $\mathrm{P}=$ productivity $(\mathrm{g} . \mathrm{L}-1 . \mathrm{h}-1) ; \mathrm{Po}=$ initial product mass $(\mathrm{g} . \mathrm{L}-1)$; Pf = mass of final product (g.L-1); tf = final fermentation time (h); to = initial fermentation time (h).

\section{Results and Discussions}

\subsection{Fermentation with yeast Saccharomyces cerevisiae}

The fermentation was carried out in synthetic culture medium (MS), crude hydrolyzed medium (MH) and detoxified hydrolyzed medium (MHD), with a constant temperature of $30{ }^{\circ} \mathrm{C}$; with initial $\mathrm{pH}$ of 6.5 and initial substrate (glucose) 5\% (w/v); where aliquots were removed every 2 hours, after the first 4 hours of fermentation for 24 hours.

\subsubsection{Change in $\mathrm{pH}$ in the culture medium}

The initial $\mathrm{pH}$ of the culture media for fermentation containing, synthetic medium (MS), rice husk hydrolyzate $(\mathrm{MH})$ and detoxified hydrolyzate (MHD) was 6.5. Figure 1 shows the performance in relation to $\mathrm{pH}$ during the alcoholic fermentation process during the 24 hour period. It becomes possible to see the reduction that occurred sharply during the first 12 hours, followed by a less mild reduction during the following hours. The final $\mathrm{pH}$ values after fermentation were 4.93 for hydrolyzed medium, 5.1 for detoxified and 2.93 for synthetic medium. It is possible to observe a small difference in relation to hydrolysates, however, considerable with the synthetic medium.

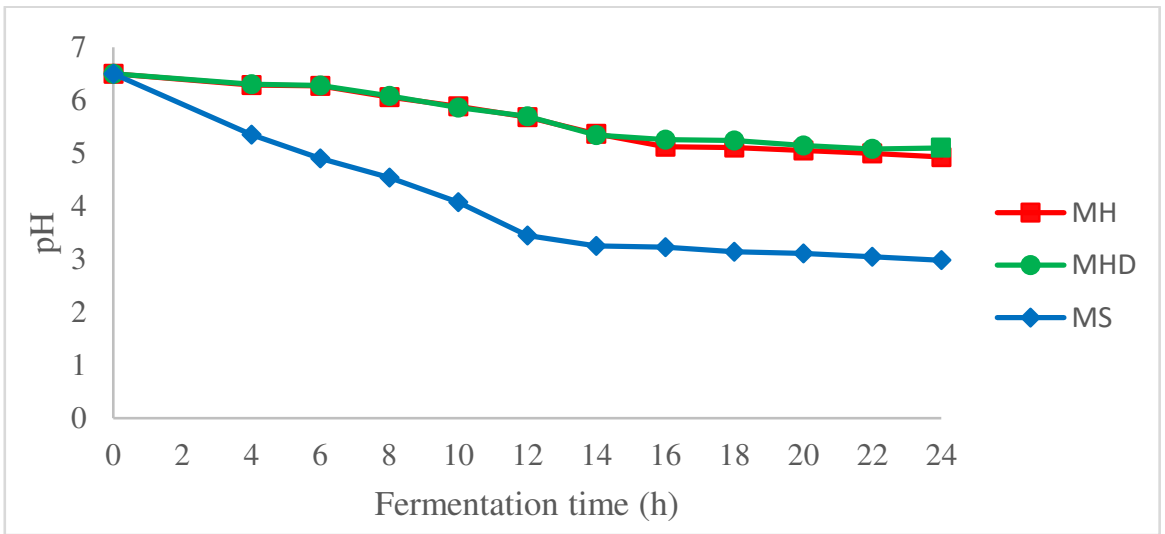

Fig 1. Kinetics of the fermentations pH by Saccharomyces cerevisiae during the 24-hour period determined in the 2-hour interval in the MS, MH and MHD media. 
The performance of $\mathrm{pH}$ during the fermentation process acts directly on its yield, considering that these changes can influence the metabolism of the micro-organism as well as yield in the process. PH can play an important role in the face of fermentative inhibition, and consequently lead to changes in cellular metabolism. During ethanol production, the $\mathrm{pH}$ of the medium tends to decrease due to the consumption of substrates and byproduct formations, as it gradually decreases during this process (16).

\subsubsection{Cell Growth (Biomass)}

The inoculum of the yeast $S$. cerevisiae in the fermentation media was used to evaluate cell growth. Figure 2 shows the results obtained in the fermentations during the 24 hour period. This Figure shows that with the passage of time during the fermentation process, biomass increased for the 3 media used during this process (MH, MHD and MS). It would be possible to note that the synthetic medium (DM) has a higher biomass production compared to hydrolysates, such as an addition during the 12-hour period, it even produces $1.97 \mathrm{mg} /$ $\mathrm{mL}$ at the end of the 24-hour process. For the hydrolyzed and detoxified media, they were very similar for the production of biomass during the fermentation process, with a greater production during the period of 10 hours and ending with a production of $1.2 \mathrm{mg} / \mathrm{mL}$ and $1.27 \mathrm{mg} / \mathrm{mL}$ respectively.

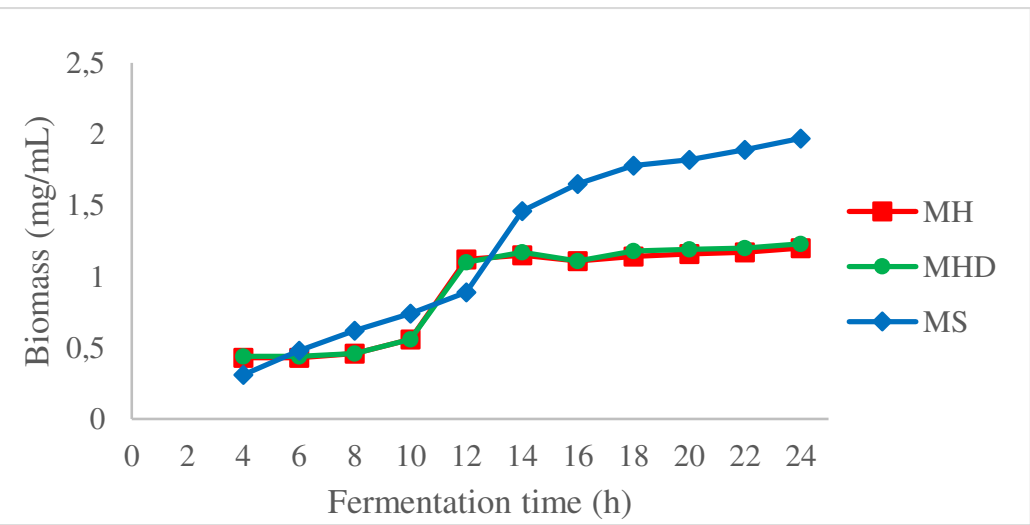

Fig 2. Kinetics of cell biomass growth of Saccharomyces cerevisiae during the 24-hour period in the 2-hour interval.

In a study on separation methods to distinguish the cell growth phases of Saccharomyces cerevisiae, researchers (17) determined the highest biomass production in the first 10 hours, following a reduction thereafter, in a culture medium with initial $\mathrm{pH} 5$, testing temperatures of 25 and $30{ }^{\circ} \mathrm{C}$. What differs from the present study, in which yeast showed the highest production after $12 \mathrm{~h}$, with successive growth until the end of fermentation $(24 \mathrm{~h})$ at $30^{\circ} \mathrm{C}$.

\subsubsection{Production of second generation bioethanol by the yeast Saccharomyces cerevisiae}

Figure 3 shows the results of ethanol production during the 24-hour fermentation, with intervals of 2 hours from the 4-hour fermentation.

The best results obtained for ethanol production were $20.6 \mathrm{mg} / \mathrm{mL}$ for synthetic medium in 24 hours, $18.67 \mathrm{mg} / \mathrm{mL}$ for hydrolyzed medium in 22 hours and $19.17 \mathrm{mg} / \mathrm{mL}$ for detoxified in 22 hours. The synthetic 
medium showed stable production until the 24-hour period while the MH and MHD showed a decrease after the 22-hour period.

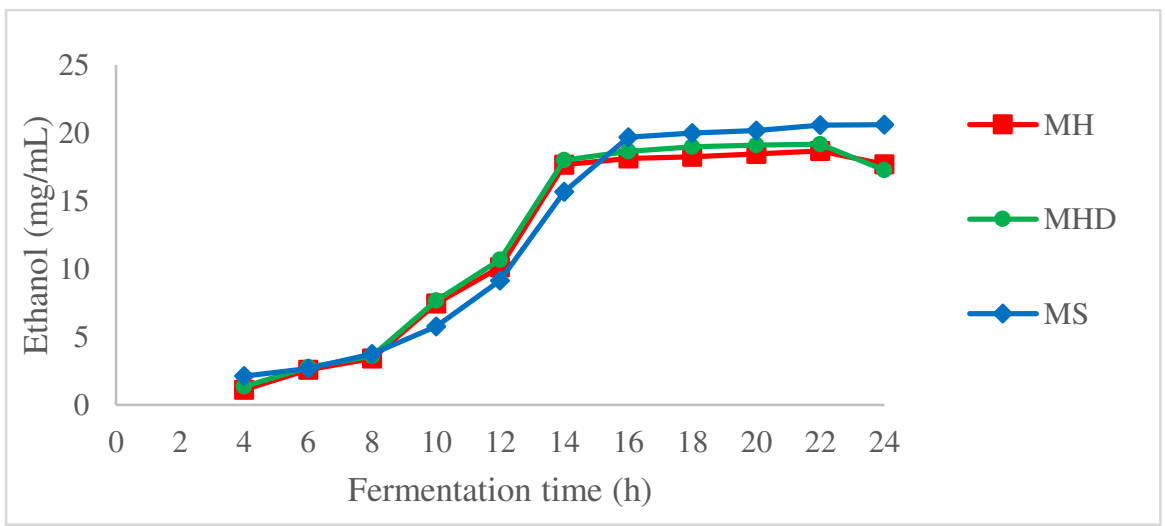

Fig 3. Kinetics of ethanol production in fermentation by Saccharomyces cerevisiae during the period of 24 hours in the interval of 2 hours.

As cell growth increased, ethanol production also increased, especially after the 12-hour fermentation period. As noted earlier in the 4 to 10 hour fermentation period, cell growth is still low, which corroborates the low ethanol production.

The authors (18) used strains of Saccharomyces cerevisiae immobilized with sodium alginate, in a concentrated bed reactor, during fermentations of 11 batch cycles, where they evaluated the consumption of the substrate (glucose) and the temperature behavior of $30{ }^{\circ} \mathrm{C}, 35^{\circ} \mathrm{C}$ and $40{ }^{\circ} \mathrm{C}$ in relation to ethanol production in these media. These researchers obtained $90 \mathrm{mg} / \mathrm{mL}$ of ethanol at the end of the batches, where there was a total consumption of the substrate. They emphasized the efficiency of ethanol production at a temperature of $30{ }^{\circ} \mathrm{C}$; the temperature with the lowest efficiency was $40^{\circ} \mathrm{C}$, the fermentation showed little consumption of glucose and ethanol production of $10 \mathrm{mg} / \mathrm{mL}$. It is possible to verify that a high ethanol content was obtained in relation to the content obtained in this research, where $18.69 \mathrm{mg} / \mathrm{mL}$ of ethanol by MH and $19.25 \mathrm{mg} / \mathrm{mL}$ by MHD when using S. cerevisiae. Where the temperature used $\left(30^{\circ} \mathrm{C}\right)$ corroborates with the authors mentioned.

\subsubsection{Productivity}

The ethanol productivity for the media used in this study is shown in Figure 4, where it is possible to verify the highest response for productivity was $1.28 \mathrm{mg} / \mathrm{mL} . \mathrm{h}$ for the detoxified medium in 14 hours, followed by the hydrolyzed medium presented 1,26 mg / mL.h in 14 hours and $1.23 \mathrm{mg} / \mathrm{mL} . \mathrm{h}$ for the synthetic medium in 16 hours. Such behavior was a reflection of the production of ethanol in hydrolyzed and detoxified media, which showed a higher production until the 14-hour fermentation period, followed by a stability in production. The behavior of the synthetic medium, in turn, showed less ethanol production in the first 16 hours of fermentation, however, after this period it was more efficient for production, following a constant increase until the end of the analysis in 24 hours.

As the fermentation proceeds, the yield decreases after 14 hours (MH, MHD) and in 16 hours (MS) this can occur due to the consumption of the substrate for growth in addition to the formation of other byproducts from the process. 


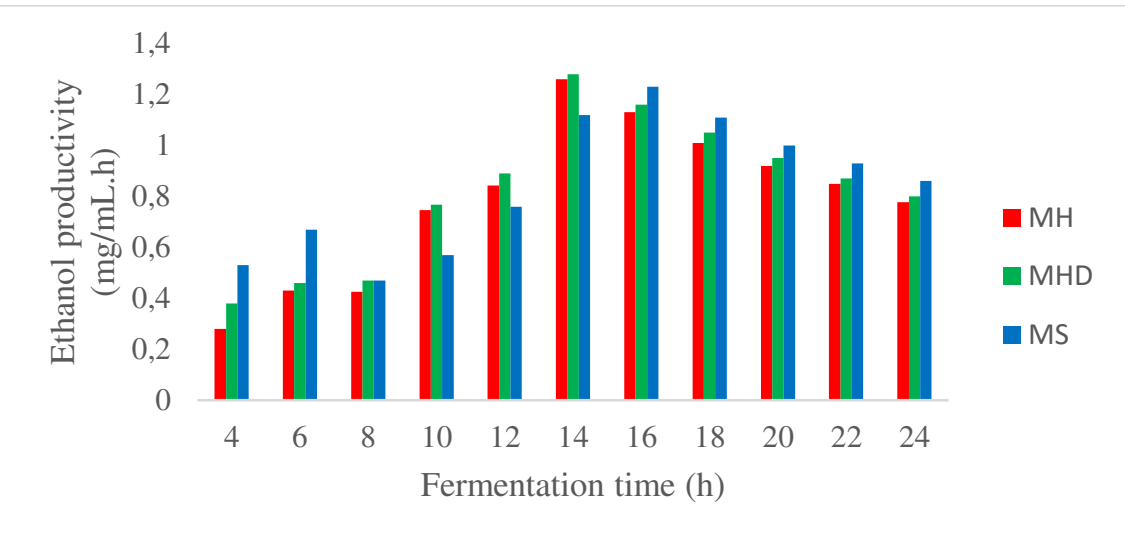

Fig 4. Productivity of ethanol in Saccharomyces cerevisiae fermentation during the 24-hour period in the 2-hour interval.

The researchers (19) used different combinations of yeast in $5 \mathrm{mg} / \mathrm{mL}$ of initial substrate in the fermentation to produce ethanol from rice husk, after 72 hours of fermentation obtained an amount of $24.4 \mathrm{mg} /$ $\mathrm{mL}$ of ethanol consuming $93 \%$ of the sugars present in the medium thus presenting a productivity of $0.56 \mathrm{mg} /$ $\mathrm{mL} . \mathrm{h}$ for the yeast Saccharomyces cerevisiae. In this work, the highest yield content obtained was $1.26 \mathrm{mg} /$ $\mathrm{mL} . \mathrm{h}$ in $14 \mathrm{~h}$ of fermentation for the hydrolyzed medium, $1.28 \mathrm{mg} / \mathrm{mL} . \mathrm{h}$ for the detoxified medium in 14 and $1.23 \mathrm{mg} / \mathrm{mL} . \mathrm{h}$ in $16 \mathrm{~h}$ for the synthetic medium.

\subsubsection{Reducing sugars in fermentation}

The reducing sugars present in the fermentation media, which were consumed by the yeast to grow and produce ethanol. Where the initial concentration was $50 \mathrm{~g} / \mathrm{L}$ for all media. Figure 5 shows during the 24 hours of the process, in which the synthetic medium obtained a higher consumption of sugars, leaving $10.5 \mathrm{~g} / \mathrm{L}$, for the hydrolyzate $16.5 \mathrm{~g} / \mathrm{L}$ and for the detoxified $12.1 \mathrm{~g} / \mathrm{L}$.

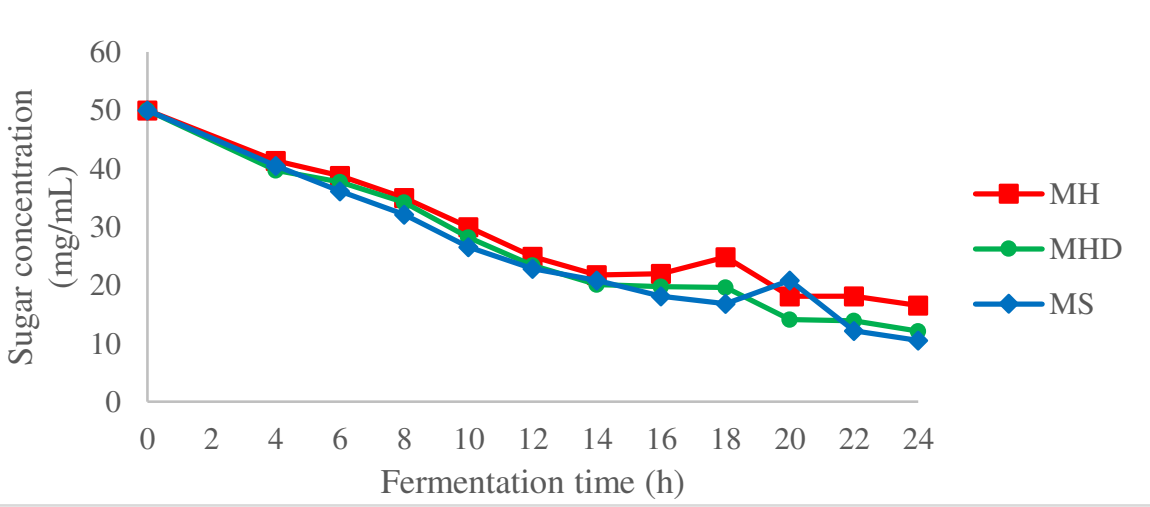

Fig 5. Sugar consumption present in the fermentation media used by Saccharomyces cerevisiae during the 24hour period in the 2-hour interval.

When using Saccharomyces cerevisiae in their study (20) aimed to produce second generation ethanol using hemicellulose hydrolysates, obtaining a production of $74.27 \mathrm{mg} / \mathrm{mL}$ of ethanol with an initial concentration of $65.17 \mathrm{mg} / \mathrm{mL}$ of sugars. The authors emphasize the effectiveness of the strategy used in this 
process, due to the presence of glucose and xylose and the consumption of both during the process within 48 hours. Consumption took place in the first 24 hours, becoming stable after this period.

\subsubsection{Fermentation with the yeast Pachysolen tannophilus}

The fermentation was carried out in synthetic culture medium (MS), crude hydrolyzate (MH) and detoxified hydrolyzate (MHD). The established parameters were a temperature of $30^{\circ} \mathrm{C}$; initial $\mathrm{pH}$ of 6.5 ; and glucose substrates 5\% (w / v); where rates were removed at times 4, 6, 8, 10, 12, 14, 16, 18, 20, 22 and 24 hours. With the best parameters determined, they were carried out for synthetic, hydrolyzed and detoxified hydrolyzed medium, during the 24-hour period.

\subsubsection{Change in $\mathrm{pH}$ in the fermentation medium}

The media used for fermentation were synthetic media containing glucose, since yeast has the capacity to produce ethanol in media containing pentoses as a substrate, and these sugars are present in the rice husk residues; rice husk hydrolyzate and detoxified hydrolyzate all with an initial $\mathrm{pH}$ of 6.5 , as well as the $\mathrm{pH}$ used for the media in the fermentation of Saccharomyces cerevisiae.

Figure 6 represents the values obtained in relation to the $\mathrm{pH}$ change of the media during the 24-hour fermentation process to obtain ethanol by the yeast Pachysolen tannophilus. The $\mathrm{pH}$ values in the hydrolyzed and detoxified medium were very similar during the fermentation, showing a small reduction, reaching the values of 5.13 and 5.12 respectively, values higher than that of the synthetic medium 3.97 at the end of 24 hours of fermentation.

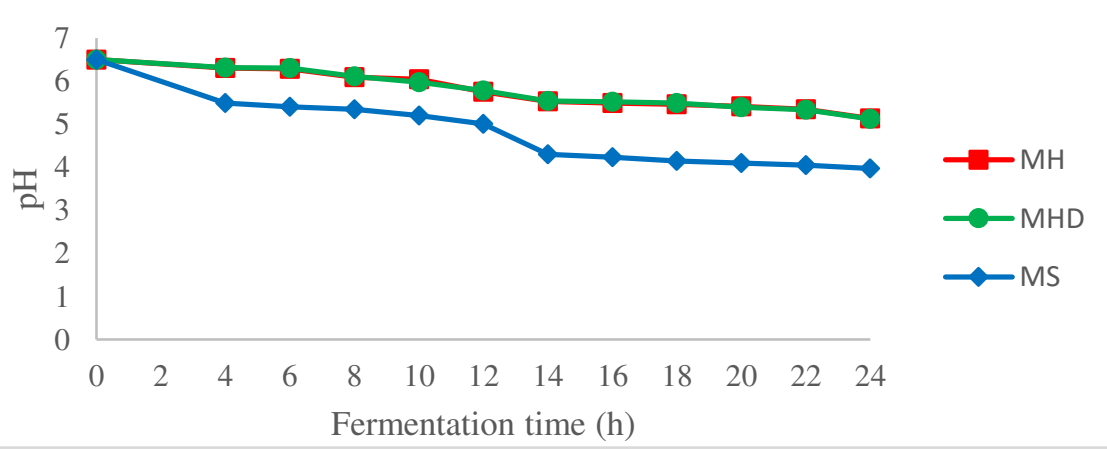

Fig 6. Kinetics of the $\mathrm{pH}$ of the fermentation by Pachysolen tannophilus during the period of 24 hours determined in the interval of 2 hours in the media MS, MH and MHD.

\subsubsection{Cell growth (Biomass) of the yeast Pachysolen tannophilus}

The yeast $P$. tannophilus immobilized in sodium alginate was evaluated in its growth during fermentation in Figure 7, which shows the results obtained during the 24-hour period. The first 4 hours were not evaluated because they are the adaptation and growth period of the yeast in the media, in this figure it is possible to observe the cellular growth of the synthetic, hydrolyzed and detoxified media. The growth becomes accentuated after 8 hours for all media, a period which was necessary for the yeast to adapt to the medium and to 
grow. The synthetic medium was less effective for the production of biomass during the first 14 hours of fermentation, when compared to the other two media in the study. The detoxified hydrolyzed medium was more effective in relation to the hydrolyzate until the period of 18 hours, after which there was a drop in which both presented similar results at the end of 24 hours, of $1.02 \mathrm{mg} / \mathrm{mL}$ and $10.3 \mathrm{mg} / \mathrm{mL}$ respectively the synthetic medium had a biomass production of $1.54 \mathrm{mg} / \mathrm{mL}$ for the same period.

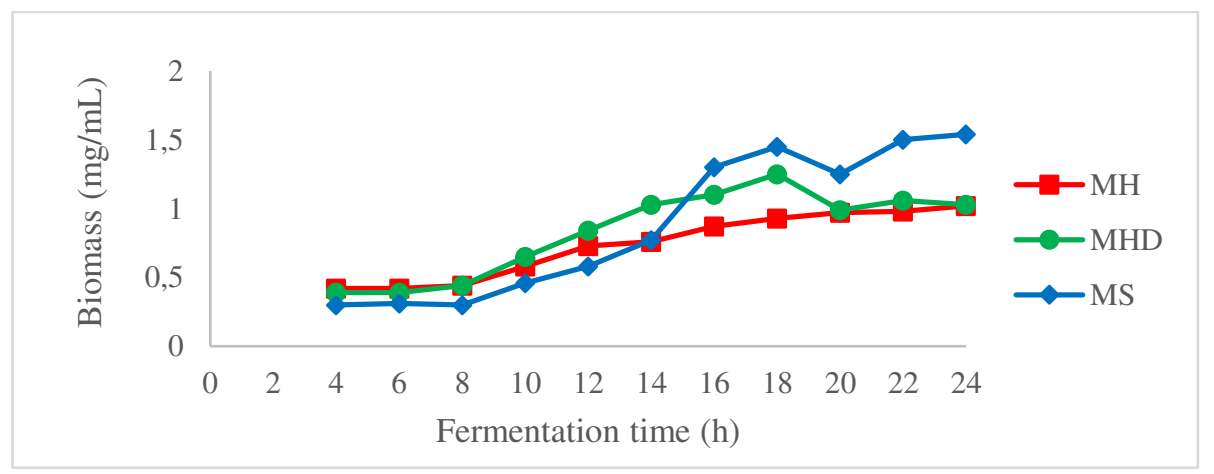

Fig.7 Growth kinetics of Pachysolen tannophilus cell biomass during the 24-hour period in the 2-hour interval

In their work, (21) studied the growth of P. tannophilus over 24 hours, using acid hydrolysates from olive residues (branches / pruning), the authors found a marked growth during 24 hours in the hydrolyzed medium with $4 \mathrm{~N}$ sulfuric acid, in comparison with one of $1 \mathrm{~N}$, reaching values of $1.62 \mathrm{mg} / \mathrm{mL}$ of cell growth and $0.75 \mathrm{mg} / \mathrm{mL}$ for $1 \mathrm{~N}$ for 20 hours. These results are similar to the results presented in this research, which were from $0.43 \mathrm{mg} / \mathrm{mL}$ to $1.20 \mathrm{mg} / \mathrm{mL}$ of cells, for the crude hydrolyzed medium and $0.44 \mathrm{mg} / \mathrm{mL}$ to 1.23 $\mathrm{mg} / \mathrm{mL}$ for the detoxified hydrolyzed medium, in $24 \mathrm{~h}$ of fermentation.

\subsubsection{Bioethanol production}

The production of ethanol by the yeast Pachysolen tannophilus during the 24 hour fermentation, with intervals of 2 hours from the 4 hour of fermentation are shown in Figure 8.

The results achieved in the production of ethanol were $11.67 \mathrm{mg} / \mathrm{mL}$ for synthetic medium in 22 hours, remaining constant in 24 hours, $8.9 \mathrm{mg} / \mathrm{mL}$ for hydrolyzed medium in 24 hours and $8.11 \mathrm{mg} / \mathrm{mL}$ for detoxified in 22 hours with a small reduction in the period of 24 hours. The synthetic medium showed increasing production up to the 24-hour period while the MH and MHD showed a decrease after the 22-hour period.

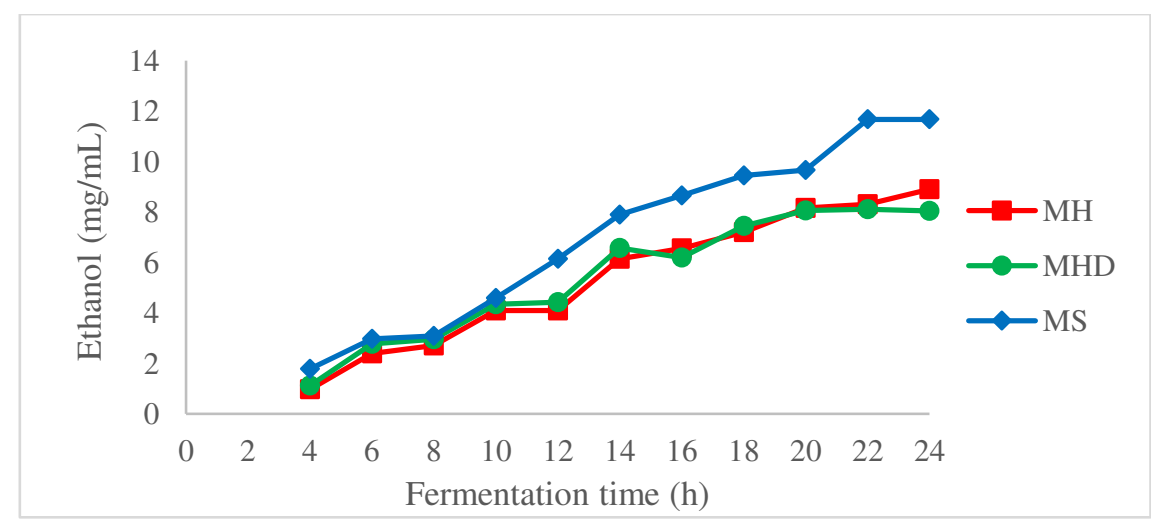

Fig.8 Kinetics of ethanol production in fermentation by Pachysolen tannophilus during the 24-hour period in the 2-hour interval 
In a study of the influence of concentrations of glucose, xylose for the production of ethanol and biomass by Pachysolen tannophilus during a period of 60 hours, where, (22) used $20 \mathrm{~g} / \mathrm{L}$ of xylose to $20 \mathrm{~g} / \mathrm{L}$ of glucose (1: 1) were $8 \mathrm{mg} / \mathrm{mL}$ for ethanol production and $5.25 \mathrm{mg} / \mathrm{mL}$ of biomass, for the medium containing only glucose the results, it was possible observe a constant drop in the amount of glucose and biomass production after the 12-hour fermentation period, since those that used only xylose as a substrate in the medium had a production of $2.93 \mathrm{mg} / \mathrm{mL}$ of ethanol and $6.5 \mathrm{mg} / \mathrm{mL}$ of biomass, notice a drop in ethanol production after 50 hours of fermentation. Using the xylose medium, the yeast obtained greater cell growth, however this was not reflected in the production of ethanol, which was inferior to the medium with glucose. For the medium containing glucose and xylose the authors showed results of $4 \mathrm{mg} / \mathrm{mL}$ of ethanol during the 35-hour fermentation period, followed by a drop in production after this period for cell growth values were $6.5 \mathrm{mg} / \mathrm{mL}$ at end of the fermentation period. These results are inferior to those of this work, where in $8.1 \mathrm{~h}$ of fermentation $8.16 \mathrm{mg} / \mathrm{mL}$ of ethanol was obtained in the hydrolyzed medium and in $22 \mathrm{~h}$ in $8.11 \mathrm{mg} / \mathrm{mL}$ was identified for the detoxified medium.

\subsubsection{Productivity}

The productivity of ethanol by the yeast Pachysolen tannophilus below compared to Saccharomyces cerevisiae the period of greatest productivity was in the period of 14 hours for all media. The results shown in figure 9, makes it possible to observe that the synthetic medium presented better yields when compared to the others reaching $0.56 \mathrm{~g} / \mathrm{Lh}$, other results obtained for that period were 0.44 and $0.47 \mathrm{mg} / \mathrm{mL}$.hpara the hydrolyzed and detoxified medium, respectively. Despite the fact that in the production of ethanol P. tannophilus continued to produce more and more until the end of the process, in this 14-hour period the yeast adapted to the medium and grew in a way that s. $u$ ethanol production was more efficient and in greater quantity compared to the previous period. The hydrolyzed medium showed lower productivity compared to the detoxified one, however, the period of 20 hours stabilized and later presented a higher productivity.

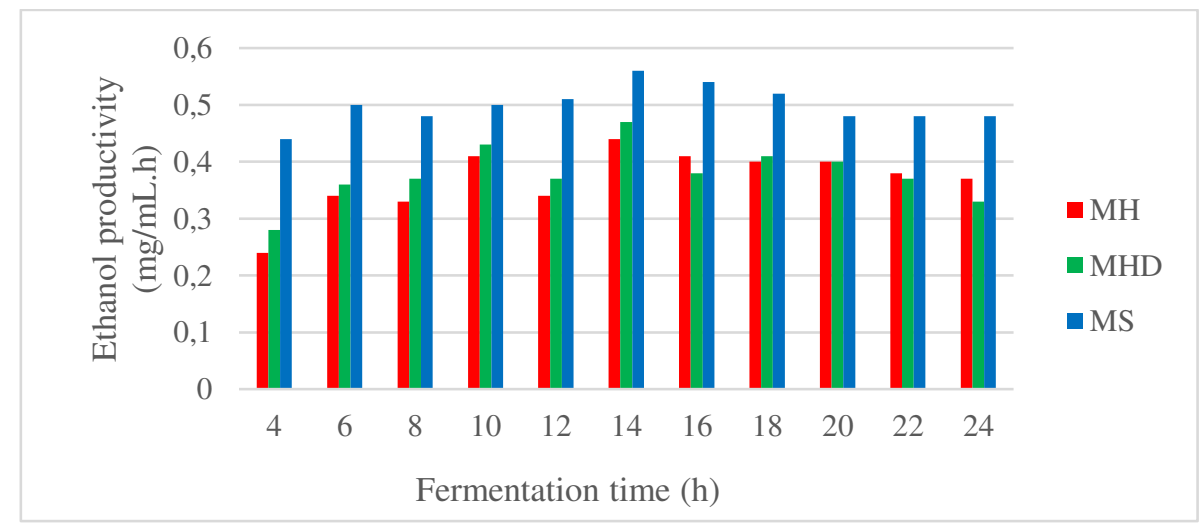

Fig 9. Productivity of ethanol in fermentation by Pachysolen tannophilus during the period of 24 hours in the interval of 2 hours.

The use of immobilized P. tannophilus was positive for ethanol production, (23) reports the use of yeast immobilized in cryogel using glycerol as a substrate. An ethanol production of $8.2 \mathrm{mg} / \mathrm{mL}$ and a yield of $0.23 \mathrm{mg} / \mathrm{mL}$ were observed. h, reporting the efficiency of immobilized yeast, as this technology increases 
productivity and improves control during the process. The productivity achieved in this research was $0.44 \mathrm{mg} /$ $\mathrm{mL} . \mathrm{h}$ for the hydrolyzed medium, $0.47 \mathrm{mg} / \mathrm{mL}$.h for the detoxified hydrolyzate is $0.56 \mathrm{mg} / \mathrm{mL} . \mathrm{h}$ all in 14 hours of fermentation being higher than the productivity achieved by the mentioned author.

\subsubsection{Consumption of reducing sugars during fermentation}

The sugars that were used by the yeast Pachysontannophilus as a substrate for fermentation and ethanol production to occur. Where the initial concentration was $50 \mathrm{mg} / \mathrm{mL}$ for all media. Figure 10 shows during the 24 hours of the process, in which the synthetic medium obtained a higher consumption of sugars, with $15.97 \mathrm{mg} / \mathrm{mL}$ remaining, for the hydrolyzate 18.2 and $17.7 \mathrm{mg} / \mathrm{mL}$ for the detoxified one.

The consumption took place with greater efficiency after the period of 8 hours of fermentation, for all the studied means in this fermentative process. After this period, the yeast adapted to the medium and obtained greater cell growth, thus leading to a greater consumption of sugars present until the end of the 24-hour fermentation process.

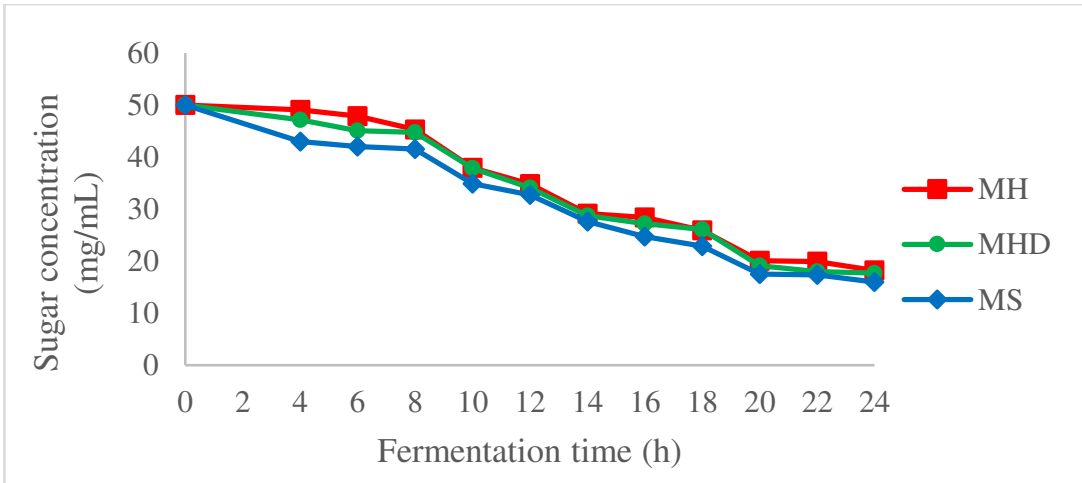

Fig 10. Sugar consumption present in the fermentation media used by Pachysolen tannophilus during the 24hour period in the 2-hour interval.

Liu et al. (2012)

(24) used glycerol for the production of ethanol by Pachysolen tannophilus during the period of 90 hours of fermentation with an initial concentration of $25 \mathrm{mg} / \mathrm{mL}$. Ethanol production was $6 \mathrm{mg} / \mathrm{mL}$ at the end of the evaluated process, in the same period all glycerol in the medium was consumed by the yeast. In the 25 hour period similar to the present study, glycerol consumption was low reaching a concentration of $20 \mathrm{mg} / \mathrm{mL}$ in the medium and a production of $2 \mathrm{mg} / \mathrm{mL}$ of ethanol for the same time.

\subsubsection{Fermentation by intercropping of microorganisms}

For the intercropping of Saccharomyces cerevisiae and Pachysolen tannophilus yeasts, the same conditions used for fermentation of hydrolysates and synthetic medium were tested. These conditions were determined by the best results in the tests previously tested for both microorganisms. Concentration of $5 \%$ of substrate was used for fermentation with an initial $\mathrm{pH}$ of 6.5 , temperature of $30{ }^{\circ} \mathrm{C}$ and static agitation $(0 \mathrm{rpm})$. Initially, Saccharomyces cerevisiae immobilized in sodium alginate during the first 12 hours was inoculated, later it was replaced in the media by Pachysolen tannophilus immobilized in sodium alginate. The parameters 
were analyzed in relation to $\mathrm{pH}$, reducing sugars, ethanol production and cell growth from 4 hours of fermentation in the intervals of 2 hours until the end of 24 hours.

\subsubsection{Change in $\mathrm{pH}$ in the culture medium}

The synthetic medium showed a greater drop in $\mathrm{pH}$ according to the fermentation time with 4.31 after 24 hours, the hydrolyzed and detoxified hydrolyzed media had a very similar $\mathrm{pH}$ ending the process period with 5.01 and 5 respectively according to figure 11. The replacement of the yeasts occurred after 12 hours, which led to a period of adaptation of $P$. tannophilus in the medium, in view of the drop in $\mathrm{pH}$ in these processes, it occurred in a more linear way, as the yeast needed time to develop and produce ethanol.

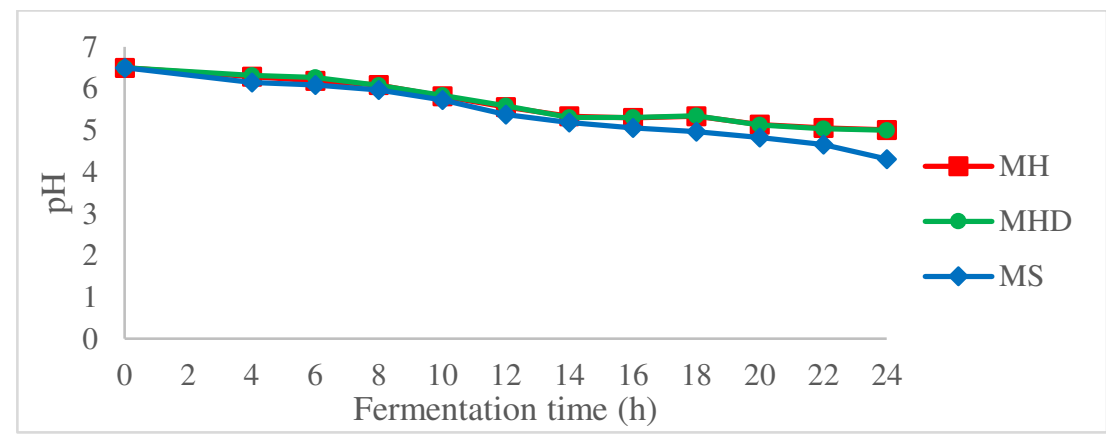

Fig 11. Fermentation pH kinetics by the consortium of Saccharomyces cerevisiae and Pachysolen tannophilus during the 24-hour period determined in the 2-hour interval in the MS, MH and MHD media.

Ethanol production by kitchen waste (food waste), by the co-fermentation of Saccharomyces cerevisiae and Pichia stipits were a study (25), who used different substrate concentrations of $20 \mathrm{mg} / \mathrm{mL}, 40$ $\mathrm{mg} / \mathrm{mL}, 60 \mathrm{mg} / \mathrm{mL}$, with different concentrations of initial $\mathrm{pH} \mathrm{5,} \mathrm{5.4,} 5.8$ respectively during the 50-hour fermentation period. The media showed a sharp drop during the first 10 hours of fermentation, reaching values of $2.5 \mathrm{pH}$ for all media in 20 hours of fermentation, this value which in turn remained stable until the end in the period of 50 hours. The authors also verified the efficiency of the two yeast intercropping and its capacity to consume a greater amount of sugars present in the medium for ethanol production, as well as the capacity of these residues for the production of bioethanol.

\subsubsection{Cell Growth (Biomass)}

The yeasts $S$. cerevisiae and $P$. tannophilus were used in fermentation media to evaluate cell growth, with the first 12 hours of $S$. cerevisiae followed by $P$. tannophilus by intercropping until the end.

Figure 12 shows the results obtained in the fermentations during the time of 24 hours. This figure shows that over time during the fermentation process, biomass increased for the 3 media used during this process (MH, MHD and MS). Make it possible to note that the synthetic medium (MS) has a higher biomass production at the end of the 24 hour evaluated process compared to the hydrolysates, such as high cell growth in the detoxified hydrolyzed medium that stabilized in the 20 hour process period $1,57 \mathrm{mg} / \mathrm{mL}$, the hydrolyzed medium produced an amount of $1.18 \mathrm{mg} / \mathrm{mL}$ of biomass in 14 hours and stabilized at this value. For the hydrolyzed medium, it was less efficient for the production of biomass compared to the detoxified one using the intercropping of microorganisms. 


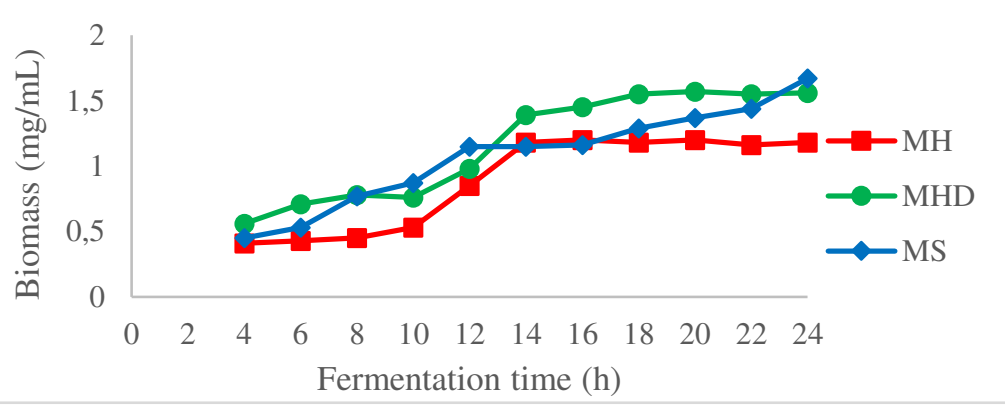

Fig 12. Kinetics of biomass growth by the Saccharomyces cerevisiae and Pachysolen tannophilus intercropping during the 24-hour period determined in the 2-hour interval.

The production of biomass and ethanol by consortium of Saccaromyces cerevisiae and Pachysolen tannophilus in synthetic medium was used (26). Parameters such as sugar consumption, ethanol production and biomass were analyzed during the 48-hour fermentation period with an initial substrate concentration of $20 \mathrm{mg} /$ $\mathrm{mL}$. The author determined greater biomass production in the 30-hour period, producing $3.91 \mathrm{mg} / \mathrm{mL}, 4.74 \mathrm{mg}$ / $\mathrm{mL}$ of residual sugar after the 48 -hour period, and his greatest ethanol production occurred in the 30-hour period. with $2.98 \mathrm{mg} / \mathrm{mL}$ using the intercrop. It was possible to verify in the study, that $100 \%$ of the glucose was consumed by the yeasts and that $10.5 \%$ of the xylose present was not consumed.

\subsubsection{Production of second generation ethanol by the microorganism consortium}

The maximum values for concentration in ethanol production obtained were $18.65 \mathrm{mg} / \mathrm{mL}$ for the hydrolyzate, $19.34 \mathrm{mg} / \mathrm{mL}$ for the detoxified hydrolyzate and $21.5 \mathrm{mg} / \mathrm{mL}$ for the synthetic medium. The synthetic medium showed better response to the consortium by the parameters used of $30^{\circ} \mathrm{C}$, static with an initial $\mathrm{pH}$ of 6.5 , the efficiency of its production increased after the period of 10 hours and remained in growth until the end of 24 hours observed in the figure 13. The hydrolyzed and detoxified media showed a very similar behavior for the production of ethanol during the 24-hour period, this behavior was also possible to be observed during cell growth and $\mathrm{pH}$.

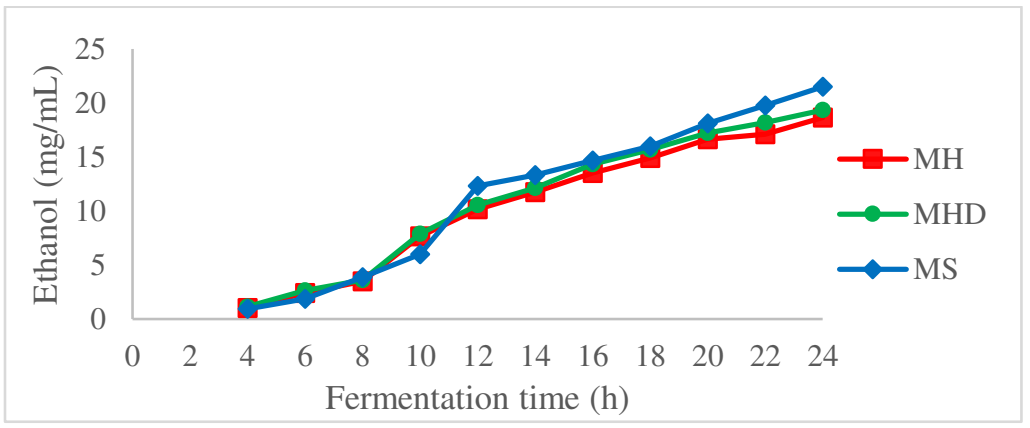

Fig 13. Kinetics of ethanol production by the Saccharomyces cerevisiae and Pachysolen tannophilus consortium during the 24-hour period determined in the 2-hour interval. 
(27) Used consortium of Saccharomyces cerevisiae and Scheffersomyces stipitis to obtain ethanol from rice husks, in this study concentrations of $10,25,50$ and $70 \mathrm{mg} / \mathrm{mL}$ were used, obtaining a production of $2.5 ; 5.5 ; 12.56$ and 20.8 respectively for 36 hours. The yeast intercropping proved to be $41 \%$ more effective than monoculture for ethanol production.

\subsubsection{Productivity}

The intercropping of the yeasts Pachysolen tannophilus and Saccharomyces cerevisiae in relation to their ethanol productivity is shown in Figure 14. It is possible to verify a higher productivity in 12 hours for synthetic medium with $1.03 \mathrm{mg} / \mathrm{mL}$.hem sequence through the detoxified medium with $0,90 \mathrm{mg} / \mathrm{mL} . \mathrm{hem}$ at 16 hours, the hydrolyzed medium showed a productivity of $0.84 \mathrm{~g} /$ L.h times 12, 14 and 16 hours later presenting a fall. The synthetic medium showed better responses after 12 hours followed by a reduction up to 24 hours, however its data were superior in relation to $\mathrm{MH}$ and MHD. The synthetic medium showed better response to the first fermentation periods of 4 to 10 hours, being superior to the synthetic and hydrolyzed medium, after presenting its peak in 16 hours, a small reduction occurred until the end of the process.

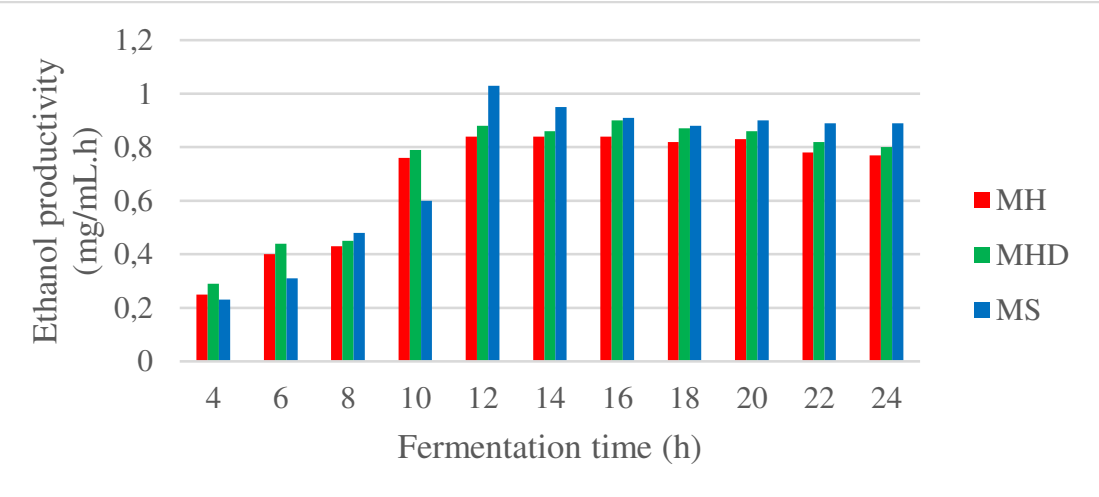

Fig 14. Ethanol productivity by the Saccharomyces cerevisiae and Pachysolen tannophilus intercropping during the 24-hour period determined in the 2-hour interval in the MS, MH and MHD media.

The effect of the immobilization of Saccharomyces cerevisiae and Pachysolen tannophilus studied in monoculture and in co-culture (28) comparing cotton stalk, chemical hydrolysis (alkaline) and enzymatic hydrolysis. The results obtained for the ethanol productivity of $S$. cerevisiae was $0.078 \mathrm{mg} / \mathrm{mL} . \mathrm{h}-1$ for the residue, $0.31 \mathrm{mg} / \mathrm{mL} . \mathrm{h}-1$ for acid hydrolysis and $0.35 \mathrm{mg} / \mathrm{mL} . \mathrm{h}-1$ for the enzyme. For the yeast $P$. tannophilus they presented respective values of $0.058 \mathrm{mg} / \mathrm{mL} . \mathrm{h}-1,0.23 \mathrm{mg} / \mathrm{mL} . \mathrm{h}-1$ and $0.21 \mathrm{mg} / \mathrm{mL} . \mathrm{h}-1$. The author emphasizes the improvement of the efficiency in the production of ethanol for the intercropping of both yeasts obtaining values of $0.098 \mathrm{mg} / \mathrm{mL} . \mathrm{h}-1,0.46 \mathrm{mg} / \mathrm{mL} . \mathrm{h}-1$ and $0.44 \mathrm{mg} / \mathrm{mL} . \mathrm{h}-1$ for the same parameters studied in monoculture, showing the effectiveness of the cell immobilization process and yeast co-culture.

\subsubsection{Consumption of Reducing Sugars in Fermentation}

The reducing sugars present in the fermentation media, which were used by the yeast intercropping for the production of ethanol. The initial concentration was given by $50 \mathrm{mg} / \mathrm{mL}$ in the hydrolyzate and in the detoxified hydrolyzate of the sugars present and for the synthetic medium the same concentration using xylose and glucose (1: 1). Figure 15 shows during the 24 hours of the process, in which the synthetic medium obtained 
a higher consumption of sugars, with $8.46 \mathrm{~g} / \mathrm{L}$ remaining, for the 13.91 hydrolyzate and $11.21 \mathrm{mg} / \mathrm{mL}$ for the detoxified one.

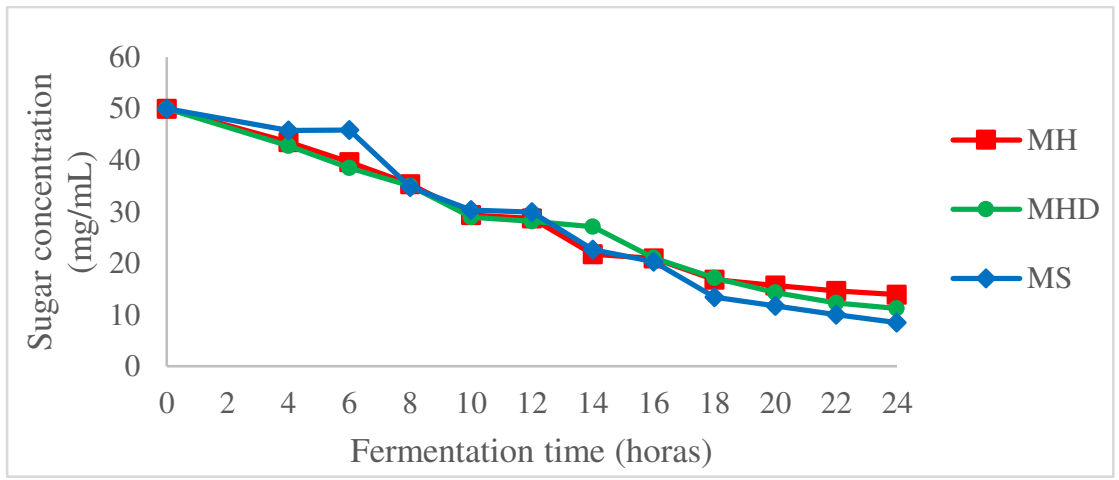

Fig 15. Sugar consumption present in the fermentation media used by the Saccharomyces cerevisiae and Pachysolen tannophilus intercropping during the 24-hour period in the 2-hour interval.

(28) Used in their study the yeasts Saccharomyces cerevisiae and Pachysolen tannophilus immobilized, individually and intercropped for the production of ethanol from cotton stalk. Three different substrate concentrations were used initially $90 \mathrm{mg} / \mathrm{mL}, 260 \mathrm{mg} / \mathrm{mL}$ and $280 \mathrm{mg} / \mathrm{mL}$ during the 96-hour fermentation period. The behavior of intercropped fermentation proved to be more effective than yeasts in separate process for the consumption of sugars present in the medium. Consortium of immobilized yeasts proved to be more effective in terms of consumption of substrates present in the medium, such as ethanol production, $S$. cerevisiae with chemical treatment had a production of $41.28 \mathrm{mg} / \mathrm{mL}$ while P. tannhophilus $29.88 \mathrm{mg} / \mathrm{mL}$, when used in combination, showed a production of $56.47 \mathrm{mg} / \mathrm{mL}$ and about $92.26 \%$ of the use of sugars in the medium. Highlighting the efficiency of yeast immobilization for the ethanol production process.

\section{Conclusions}

The yeasts Saccharomyces cerevisiae and Pachysolen tannophilus showed potential for ethanol production, highlighting the efficiency of S. cerevisiae in monoculture for productivity.

The intercropping between the two yeasts proved to be efficient and promising, due to a higher production of ethanol and consumption of fermentable sugars in lignocellulosic material compared to monoculture. Cellular immobilization in sodium alginate was effective for all parameters of the study, emphasizing the importance of this technology to improve performance and facilitate the process.

Funding Information This study was financially supported by CNPq - national council for scientific and technological development.

\section{Authors Contributions}

M. L. Bertuci: Author responsible for preparing the research project and carrying out the experiments.

M. D. Da Silva: Author responsible for revising and editing the manuscript.

J. P. Cano: Responsible for data analysis and translation of the manuscript text.

C. H. Garcia-Cruz: Responsible for the production of the project and revision of the manuscript. 
Not applicable.

\section{Consent to Participate}

All autors are consent to participate.

\section{Consent to Publish}

All autors are consent to the publish.

\section{Funding}

Not applicable.

\section{Competing Interests}

Not applicable.

\section{Availability of data and materials}

Not applicable.

\section{References}

1. Dafnomilis I, Hoefnagels R, Pratama Y W, Schott D L, Lodewijks G, Junginger M (2017) Review of solid and liquid biofuel demand and supply in Northwest Europe towards 2030 - a comparison of national and regional projections. Renewable Sustainable Energy Review.

2. Küüt A, Ilves R, Küüt K, Raide V, Ritslaid K J (2017) Influence of European Union Directives on the use of liquid biofuel in the transport sector. Procedia Engineering. 187: 30- 39.

3. Wei P, Cheng L-H, Zhang L, Xu X-H, Chen H-L, Gao C-J (2014) A review of membrane technology for bioethanol production. Renewable and Sustainable Energy Reviews. 30: 388-400.

4. Maldhure A V, Ehle J D (2013) Pyrolysis of purified kraft lignin in the presence of AlCl3 and ZnCl2. Journal of Environmental Chemical Engineering. 1: 844-849.

5. Furtado A T, Hekkert M P, Negro S O (2020) Of actors, functions, and fuels: Exploring a second generation ethanol transition from a technological innovation systems perspective in Brazil. Energy Research e Social Science. 70 .

6. Kumari D, Singh R (2018) Pretreatment of lignocellulosic wastes for biofuel production: A critical Review. Renewable and Sustainable Energy Reviews. 90: 877-891.

7. Xue J, Wu Y, Fu X, Li N, Sun J, Qiao Y (2020) Study on degradation characteristics and bacterial community structure changes of imoobilized cells in straw-alginate beads in marine environment. Bioresource Technology Reports. 10.

8. Behera S, Kar S, Mohanty R C, Ray R C (2010) Comparative study of bio-ethanol production from mahula (Madhuca latifolia L.) flowers by Saccharomyces cerevisiae and Zymomonasmobilis. Applied Energy .87: 96100.

9. Saleh M, Cuevas M, Garcia J F, Sanchez S (2014) Valorization of olive stones for xylitol and ethanol production from dilute acid pretreatment via enzymatic hydrolysis and fermentation by Pachysolen tannophilus. Biochemical Engineering Journal. 90: 286-293.

10. Gandu B, Rozenfeld S, Hirsch L O, Schechter A, Cahan R (2020) Immobilization of bacterial cells on carbon-cloth anode using alginate for hydrogen generation in a microbial electrolysis cell. Journal of Power Sources. 455. 
11. Dubois M, Gilles K A, Hamilton J K, Rebers P A, Smith F (1956) Colorimetric method for determination of sugars and related substances. Analytical Chemistry St. Paul. 28: 350-356.

12. Somogyi M (1952) Notes on sugar determination. Journal of Biological Chemistry 195: 19-22.

13. Nelson N (1944) A photometric adaptation of Somogy method for determination of glucose. The Journal of Biological Chemistry. 153: 375-380.

14. Chaovanalikit A, Wrolstad R E (2004) Total anthocyanins and total phenolics of fresh and processed cherries and their antioxidant properties. Food Chemistry and Toxicology. 69: 67-72.

15. Yoshikawa K, Hirasawa ., Shimizu H (2015) Effect of malic enzyme on ethanol production by Synechocystissp. PCC 6803. Journal of Bioscience and Bioengineering. 119: 82-84.

16. Lainioti G C, Kapolos J, Koliadima A, Karaiskakis G (2010) New separation methodologies for distinction of the growth phases of Saccharomyces cerevisiae cell cycle. Journal of chromatography A. 1217: 1813-1820. 17. Mishra A, Sharma A. K, Sharma S, Bagai R, Mathur A S, Gupta R P, Tuli D K (2016) Lignocellulosic ethanol production employing immobilized Saccharomyces cerevisiae in packed bed reactor. Renewable Energy. 1-7.

18. Sakomoto T, Hasunuma T, Hori Y, Yamada R, Kondo A (2012) Direct etanol production from hemicellulosic materials of rice straw by use of an engineered yeast strain codisplaying three types of hemicellulolytic enzymes on the surface of xylose-utilizing Saccharomyces cerevisiae cells. Journal of Biotechnology. 158: 203-210.

19. Boboescu I-Z, Gelinas M, Beigbeder J-B, Lavoi J-M (2017) A two-step optimization strategy for $2^{\text {nd }}$ generation ethanol production using softwood hemicelullosic hydrolysate as fermentation substrate. Bioresource technology.

20. Romero I, Sanchez S, Moya M, Castro E, Ruiz E, Bravo V (2007) Fermentation of olive tree prining acidhydrolysates by Pachysolen tannophilus. Biochemical Engineering Journal. 36: 108-115.

21. Zhao L, Zhang X, Tan T (2008) Influence of various glucose/xylose mixtures on ethanol production by Pachysolen tannophilus. Biomass and Bioenergy. 32: 1156-1161.

22. Karagoz P, Bill R M, Ozkan M (2019) Lignocellulosic ethanol production: Evaluation of new approaches, cell immobilization and reactor configurations. Renewable Energy.

23. Liu X, Jensen P R, Workman M (2012) Bioconversion of crude glycerol feedstocks into ethanol by Pachysolen tannophilus. Bioresource Technology. 104: 559-586.

24. Ntaikou I, Menis N, Alexandropoulou M, Antonopoulou G, Lyberatos G (2018) Valorization of kitchen biowaste for ethanol production via simultaneous saccharification and fermentation using co-cultures of the yeasts Saccharomyces cerevisiae and Pichia stipites.Bioresource Technology. 25. Da Silva, D. C. M. PRE-TRATAMENTO E HIDROLISE DA CASCA DE UVA PARA LIBERACAO DE ACUCARES FERMENTESCIVEIS. 2016. 113 f. Tese (Doutorado em Engenharia e Ciência de alimentos) Universidade Estadual Paulista, Instituto de Biociências, Letras e Ciências Exatas, São Jose do Rio Preto, 2016 26. Singh A, Bajar S, Bishnoi N R (2014) Enzymatic hydrolysis of microwave alkali pretreated rice husk for ethanol production by Saccharomyces cerevisiae, Scheffersomyces stipites and their co-culture. Fuel. 116: 699702. 

27. Malik K, Salama E-S, El-Dalatony M. M, Harraz F A, Al-Assari M. S, Zheng Y, Sharma P, Li X (2021) Cofermentation of immobilized yeasts boosted bioethanol production from pretreated cotton stalk lignocellulosic biomass: Long-term investigation. Industrial crops e Products. 159. 
Figures

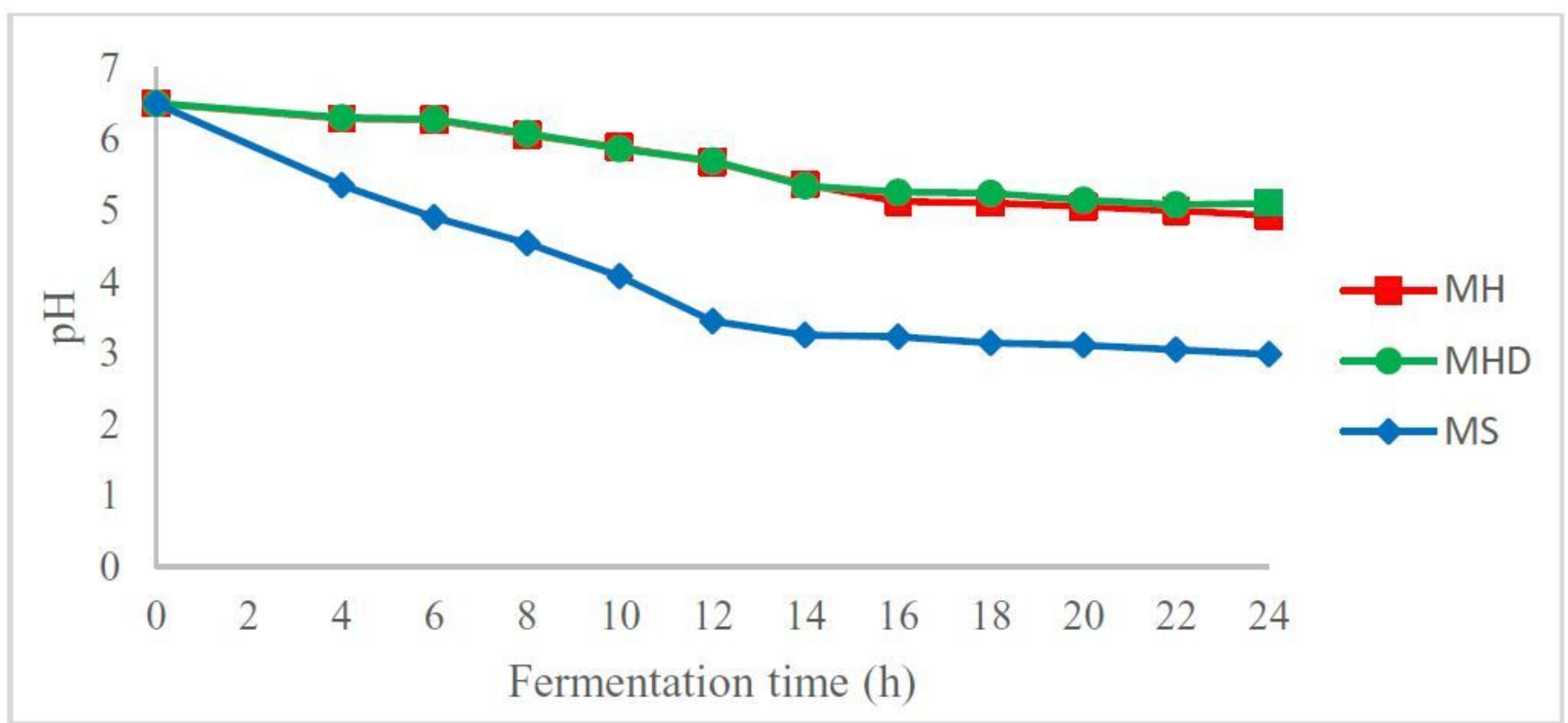

\section{Figure 1}

of the fermentations $\mathrm{pH}$ by Saccharomyces cerevisiae during the 24-hour period determined in the 2-hour interval in the MS, MH and MHD media.

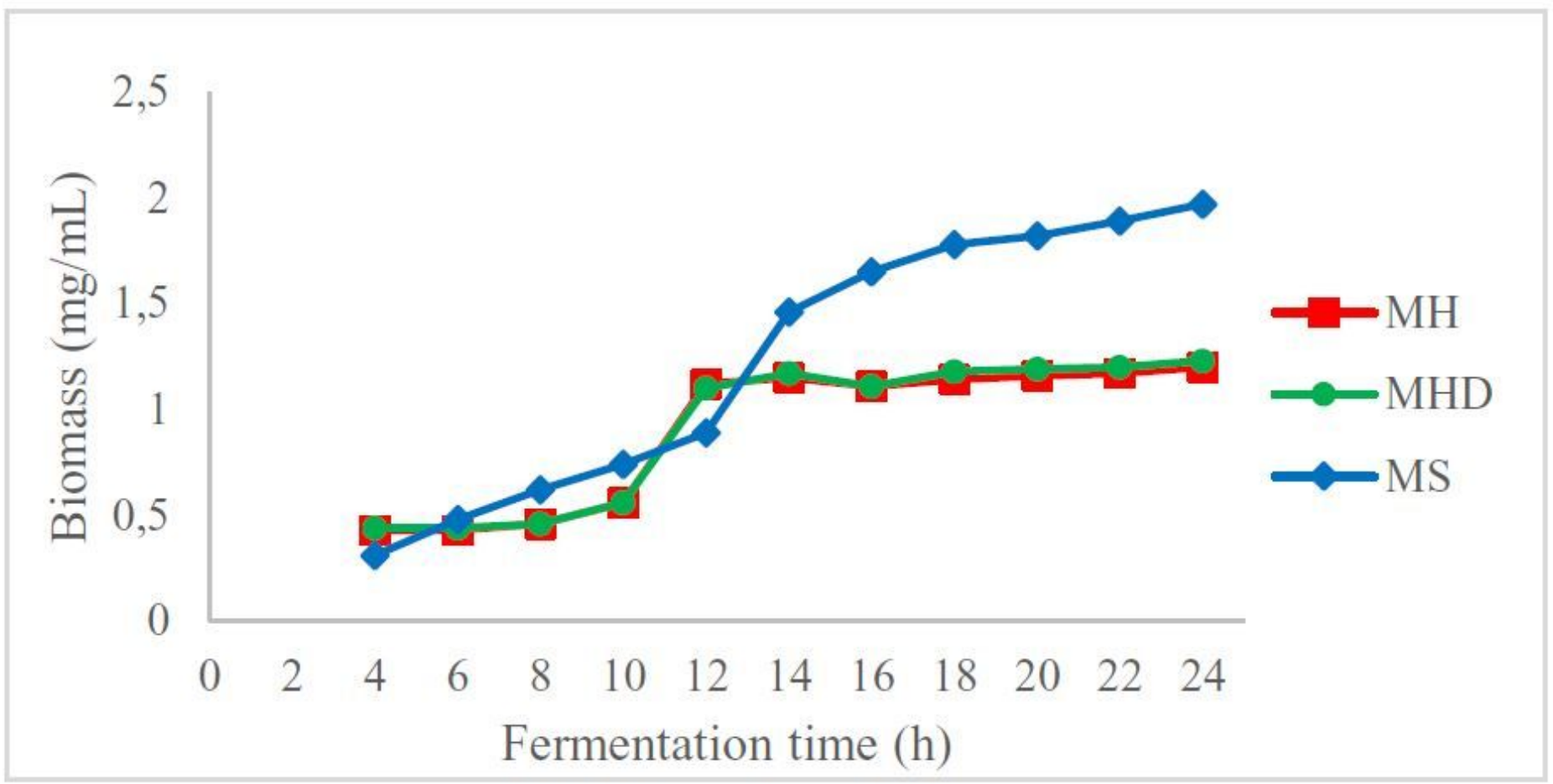

Figure 2 
Kinetics of cell biomass growth of Saccharomyces cerevisiae during the 24-hour period in the 2-hour interval.

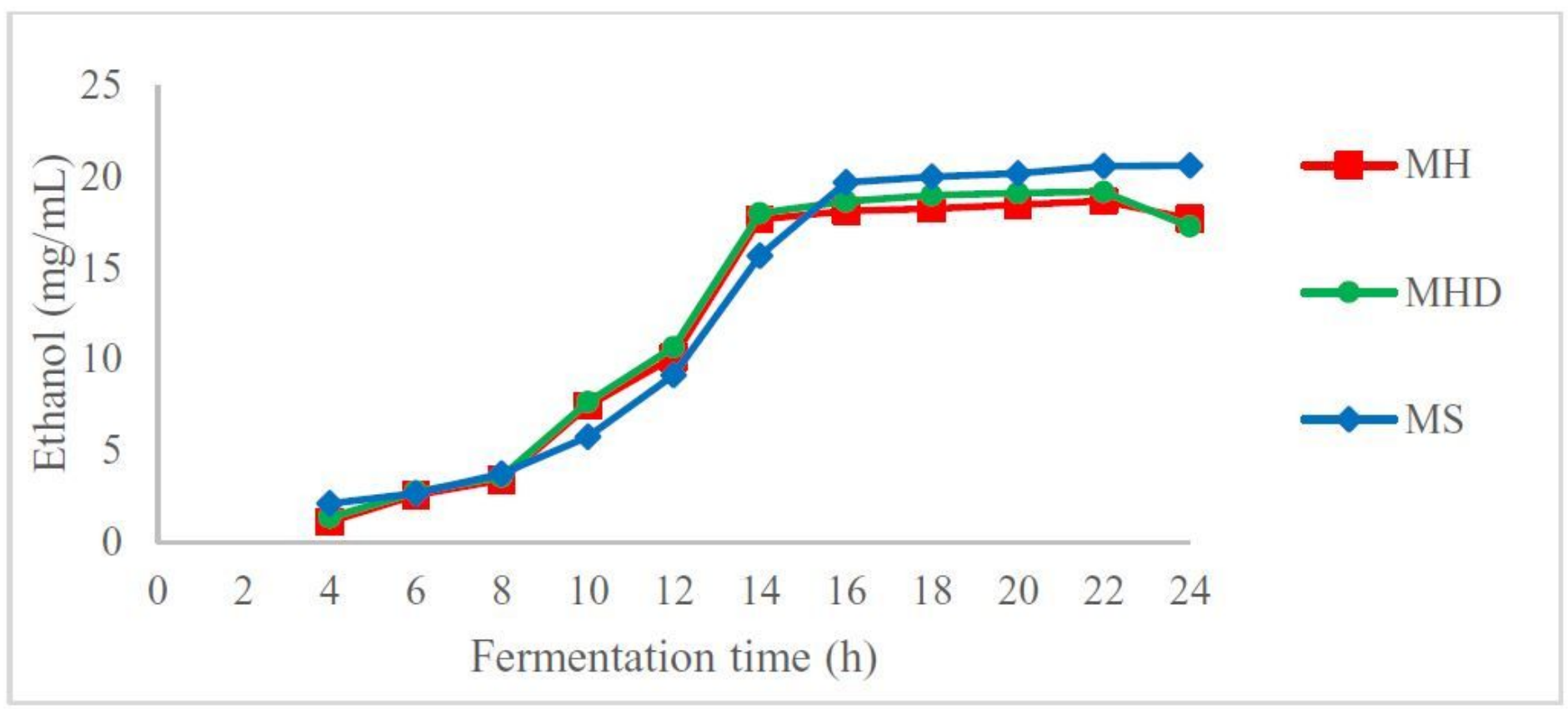

\section{Figure 3}

Kinetics of ethanol production in fermentation by Saccharomyces cerevisiae during the period of 24 hours in the interval of 2 hours.

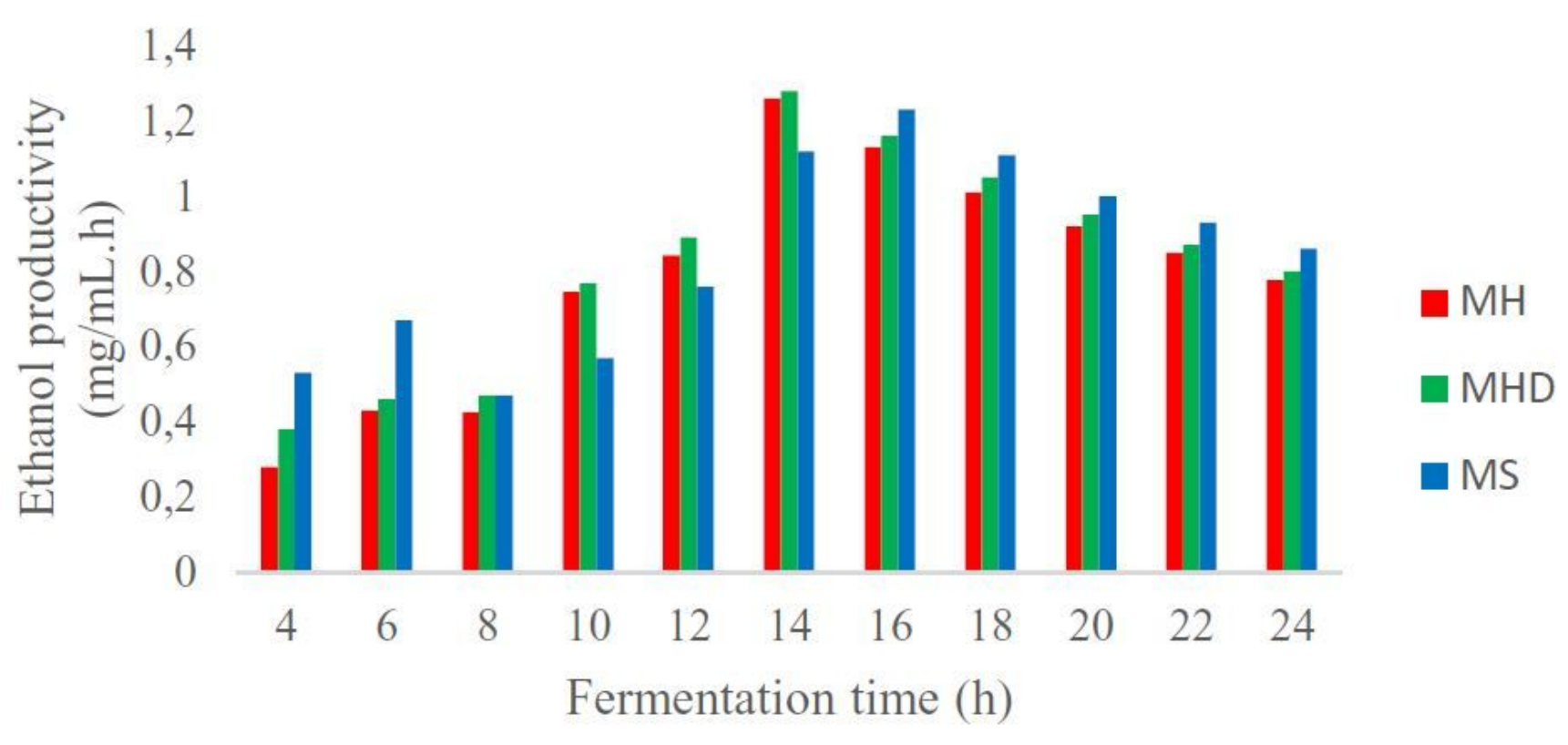

Figure 4 
Productivity of ethanol in Saccharomyces cerevisiae fermentation during the 24-hour period in the 2-hour interval.

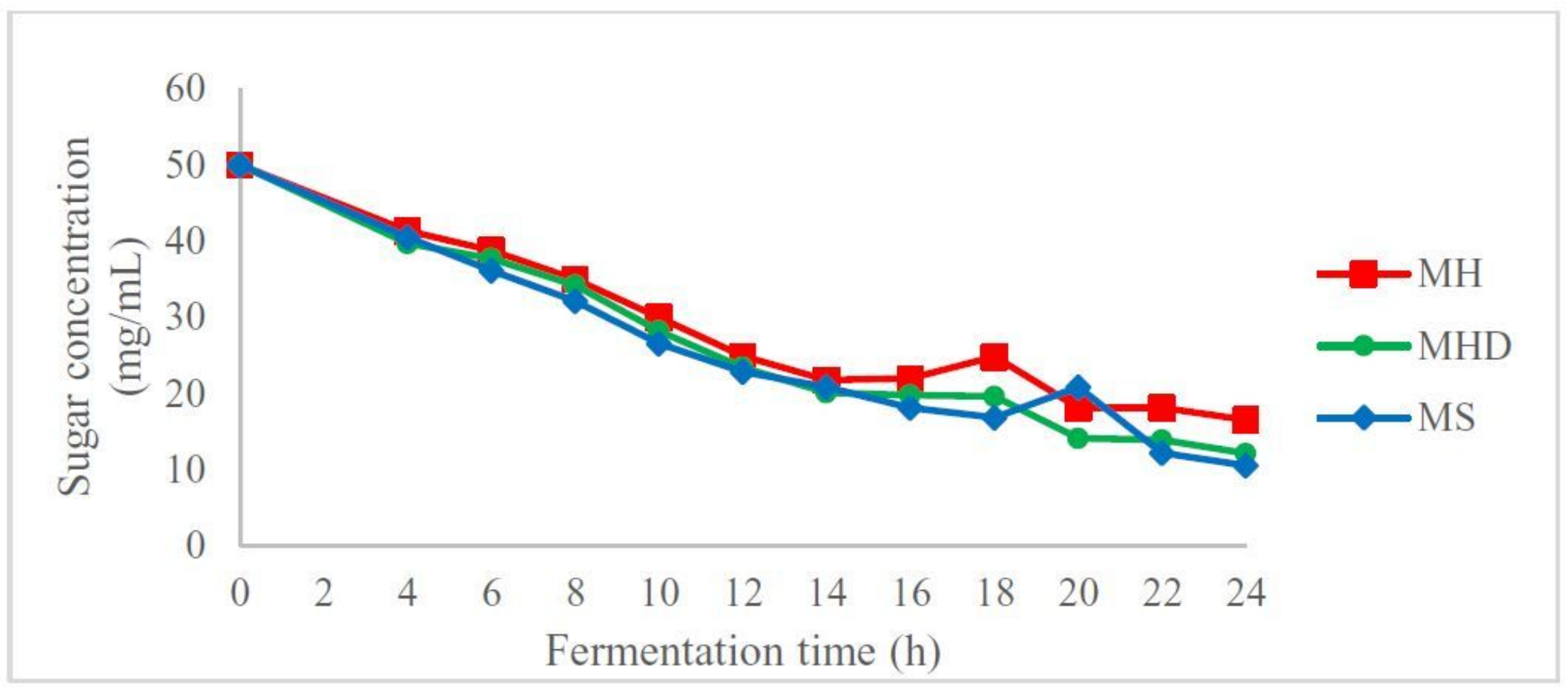

\section{Figure 5}

Sugar consumption present in the fermentation media used by Saccharomyces cerevisiae during the 24hour period in the 2-hour interval.

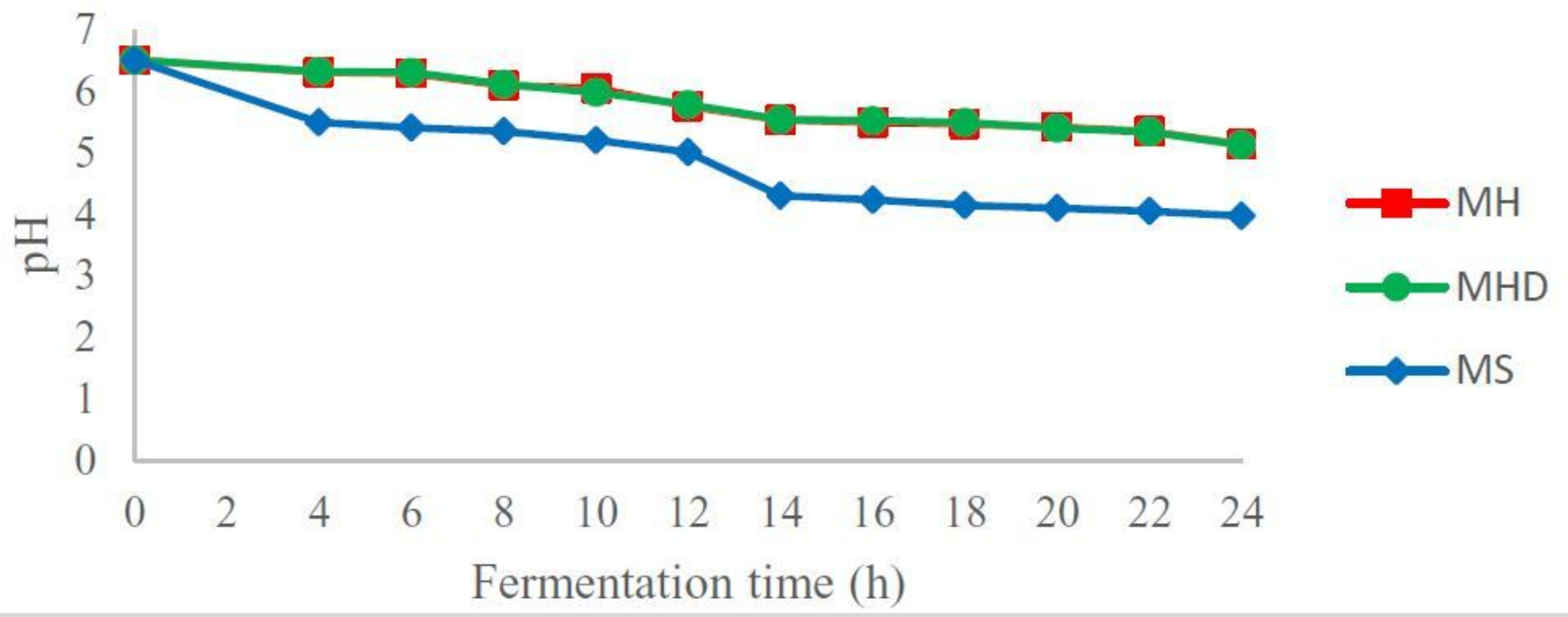

Figure 6

Kinetics of the $\mathrm{pH}$ of the fermentation by Pachysolen tannophilus during the period of 24 hours determined in the interval of 2 hours in the media MS, MH and MHD. 


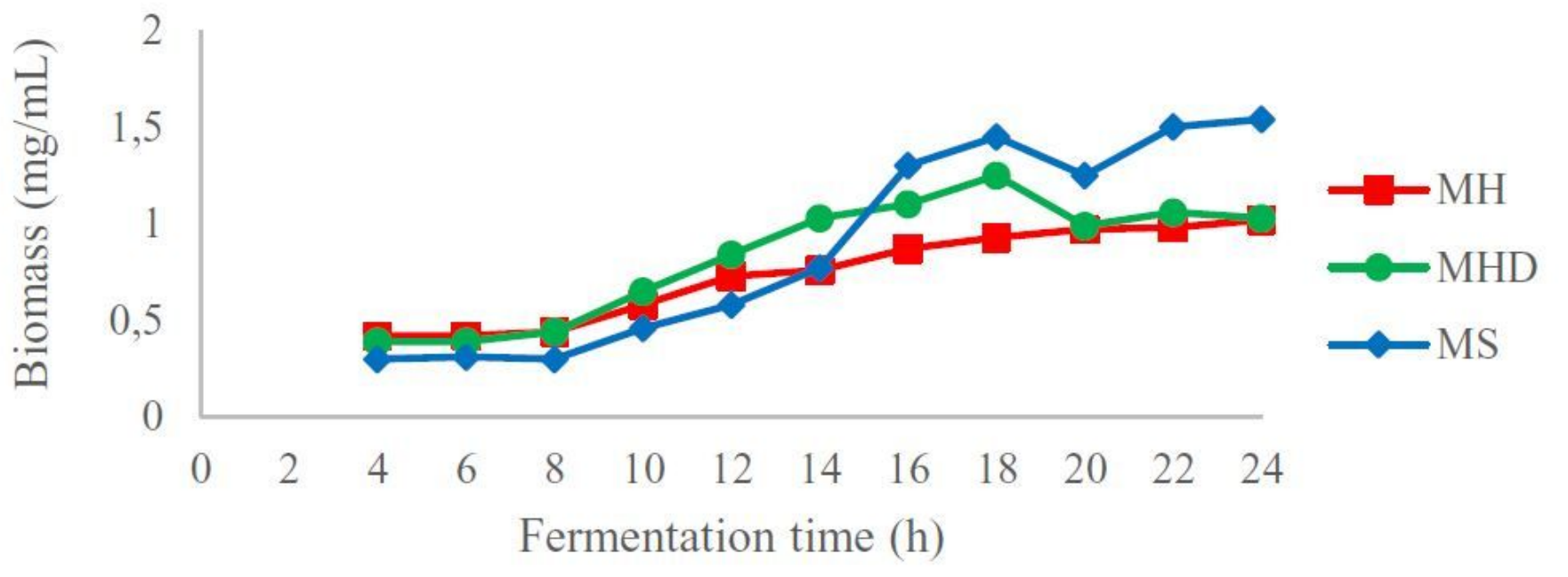

Figure 7

Growth kinetics of Pachysolen tannophilus cell biomass during the 24-hour period in the 2-hour interval

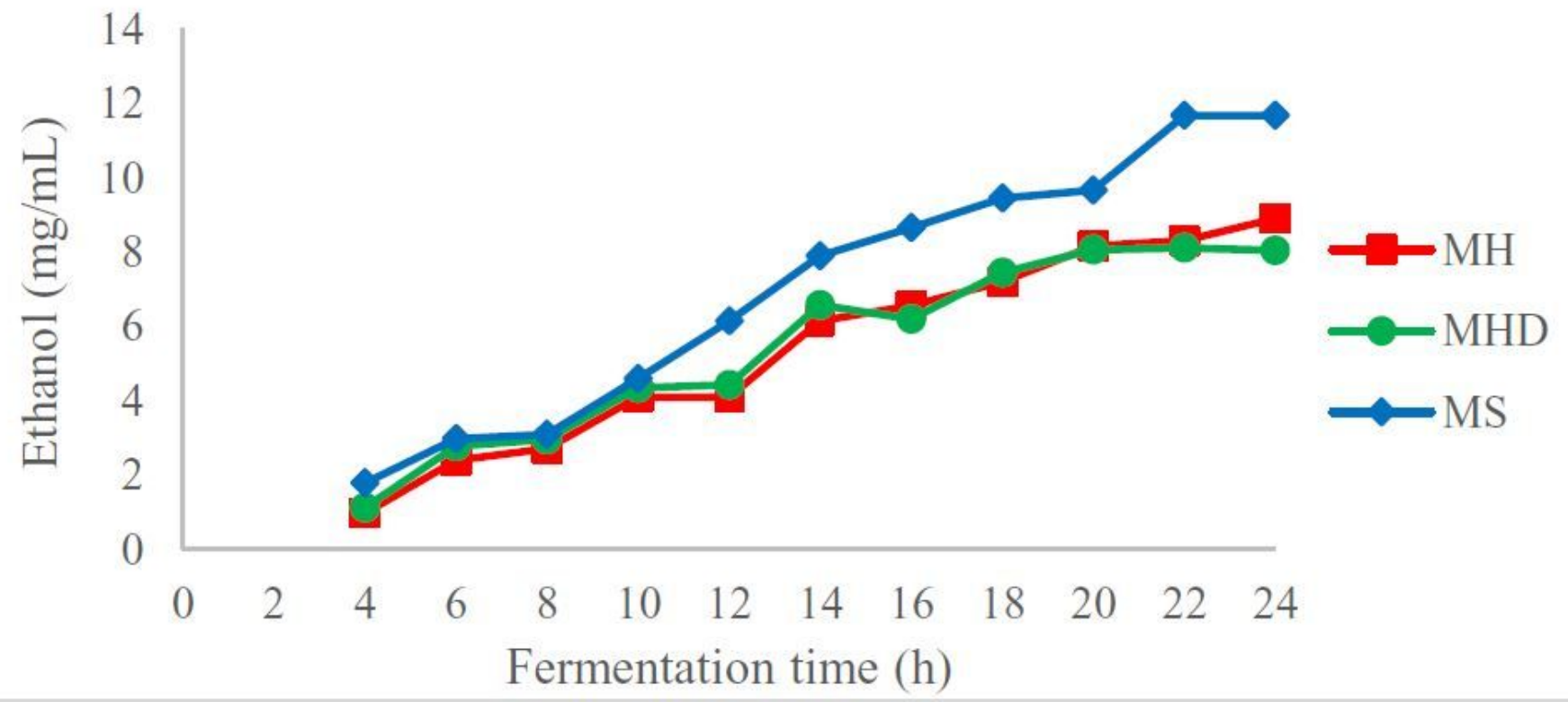

Figure 8

Kinetics of ethanol production in fermentation by Pachysolen tannophilus during the 24-hour period in the 2-hour interval 


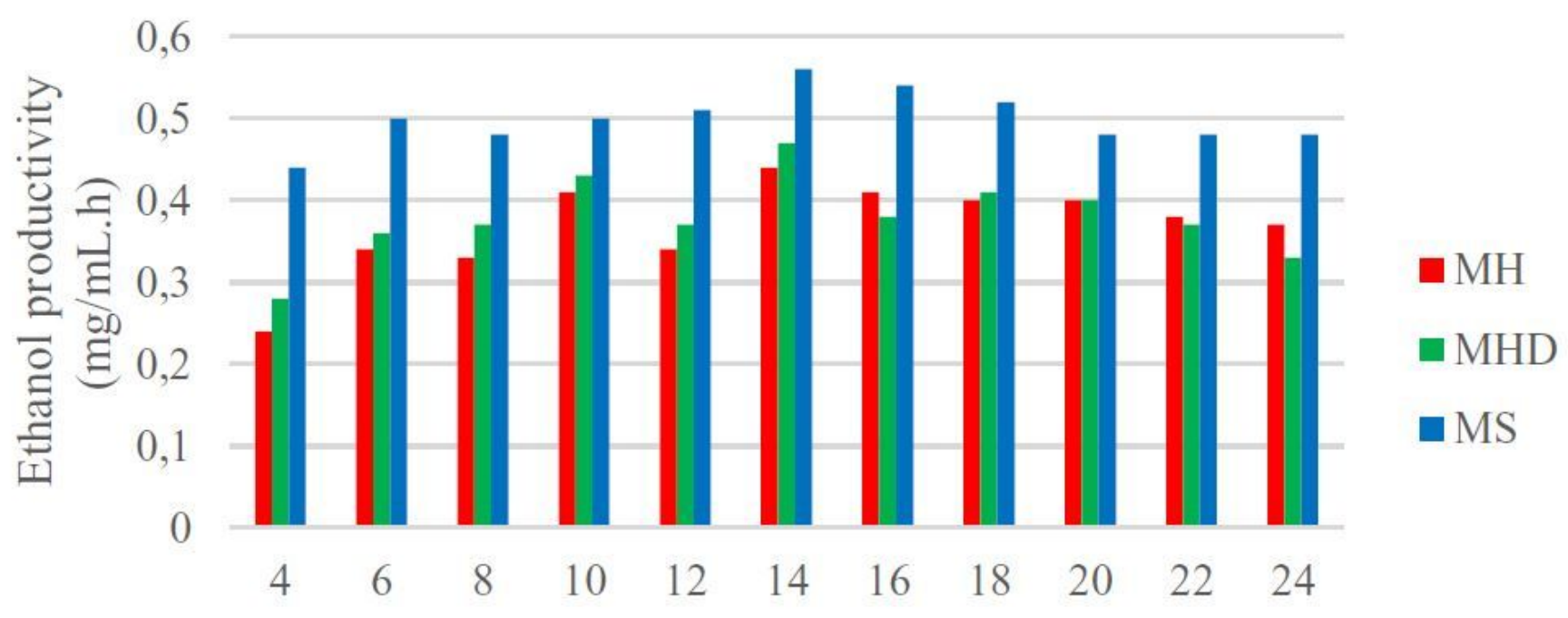

Fermentation time (h)

Figure 9

Productivity of ethanol in fermentation by Pachysolen tannophilus during the period of 24 hours in the interval of 2 hours.

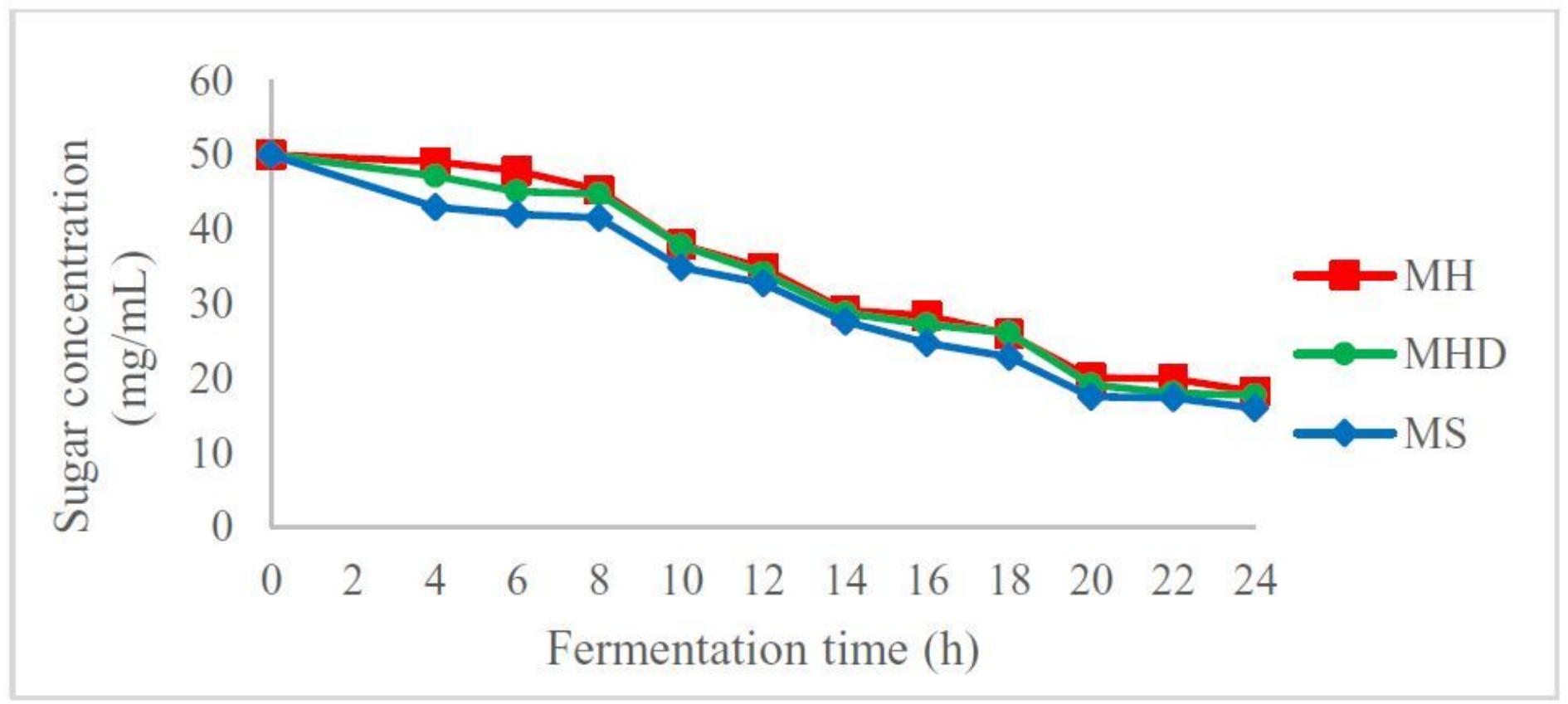

Figure 10

Sugar consumption present in the fermentation media used by Pachysolen tannophilus during the 24hour period in the 2-hour interval. 


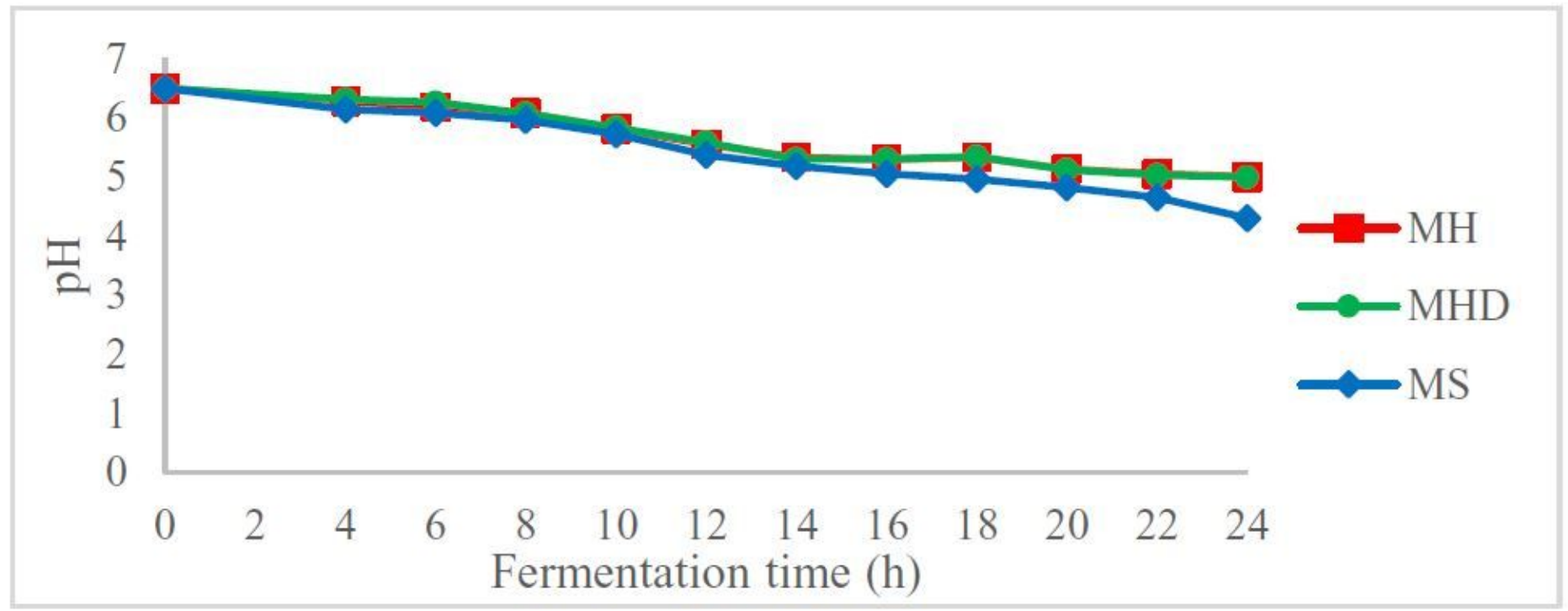

\section{Figure 11}

Fermentation $\mathrm{pH}$ kinetics by the consortium of Saccharomyces cerevisiae and Pachysolen tannophilus during the 24-hour period determined in the 2-hour interval in the MS, MH and MHD media.

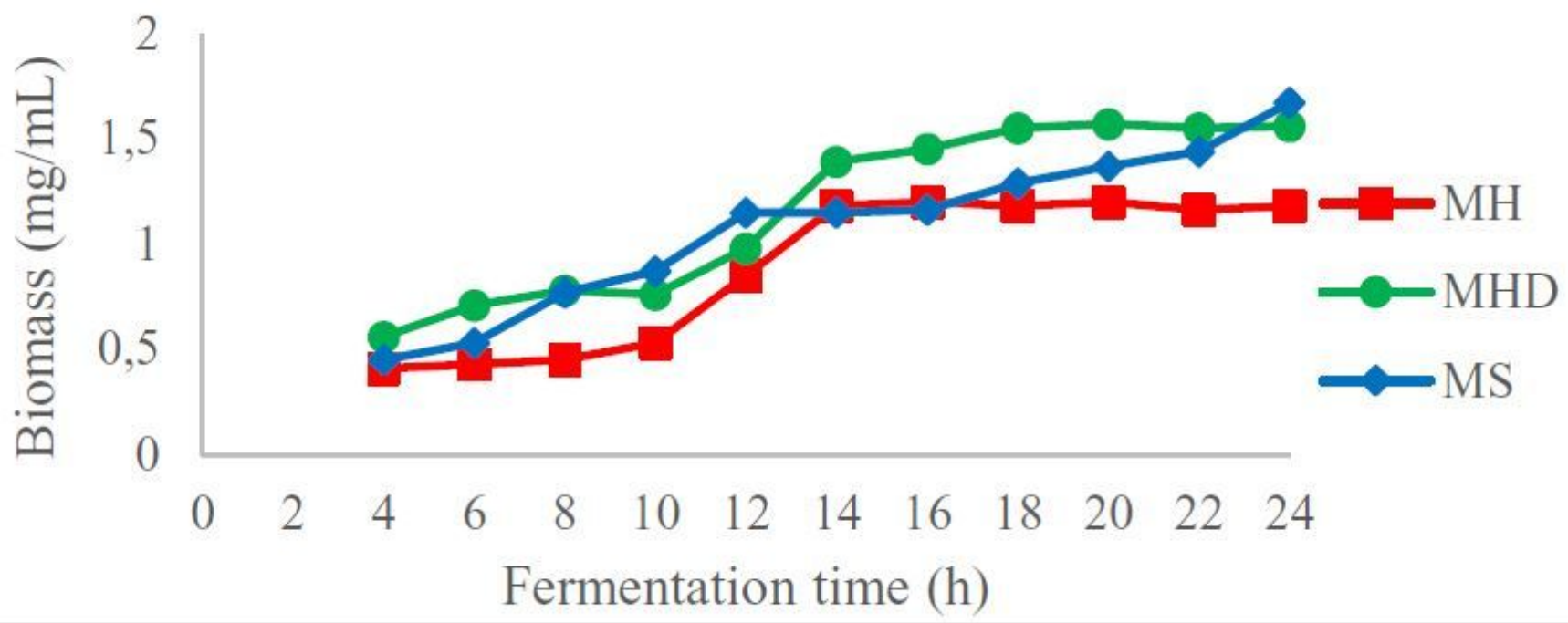

Figure 12

Kinetics of biomass growth by the Saccharomyces cerevisiae and Pachysolen tannophilus intercropping during the 24-hour period determined in the 2-hour interval. 


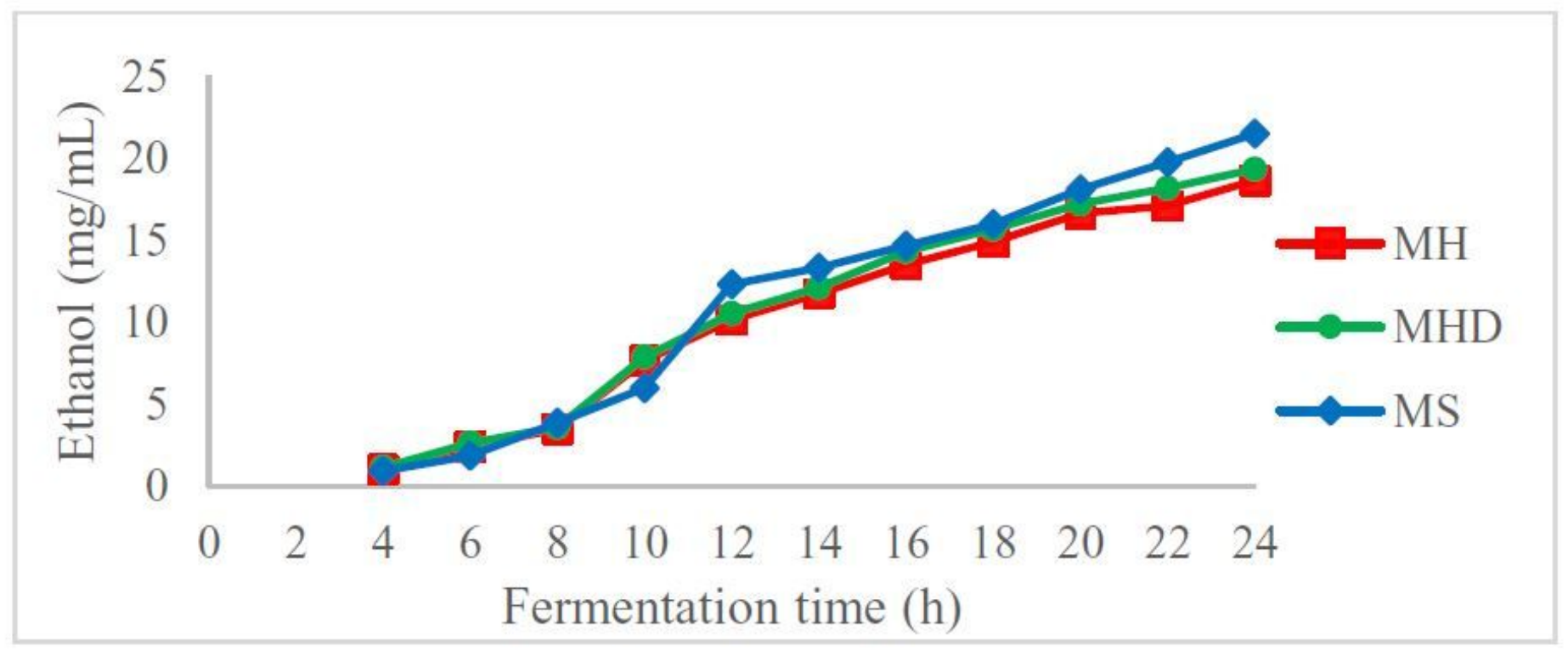

\section{Figure 13}

Kinetics of ethanol production by the Saccharomyces cerevisiae and Pachysolen tannophilus consortium during the 24-hour period determined in the 2-hour interval.

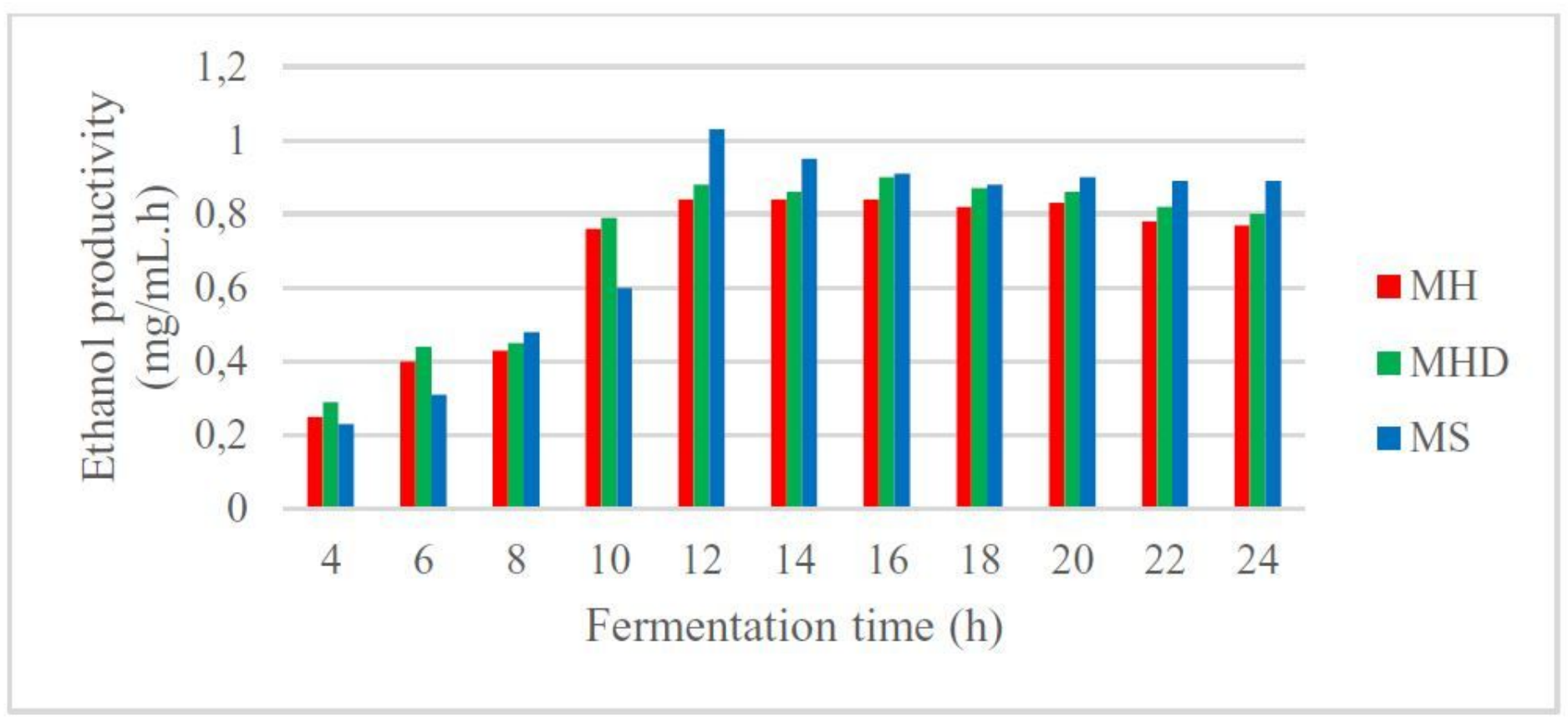

Figure 14

Ethanol productivity by the Saccharomyces cerevisiae and Pachysolen tannophilus intercropping during the 24-hour period determined in the 2-hour interval in the MS, MH and MHD media. 


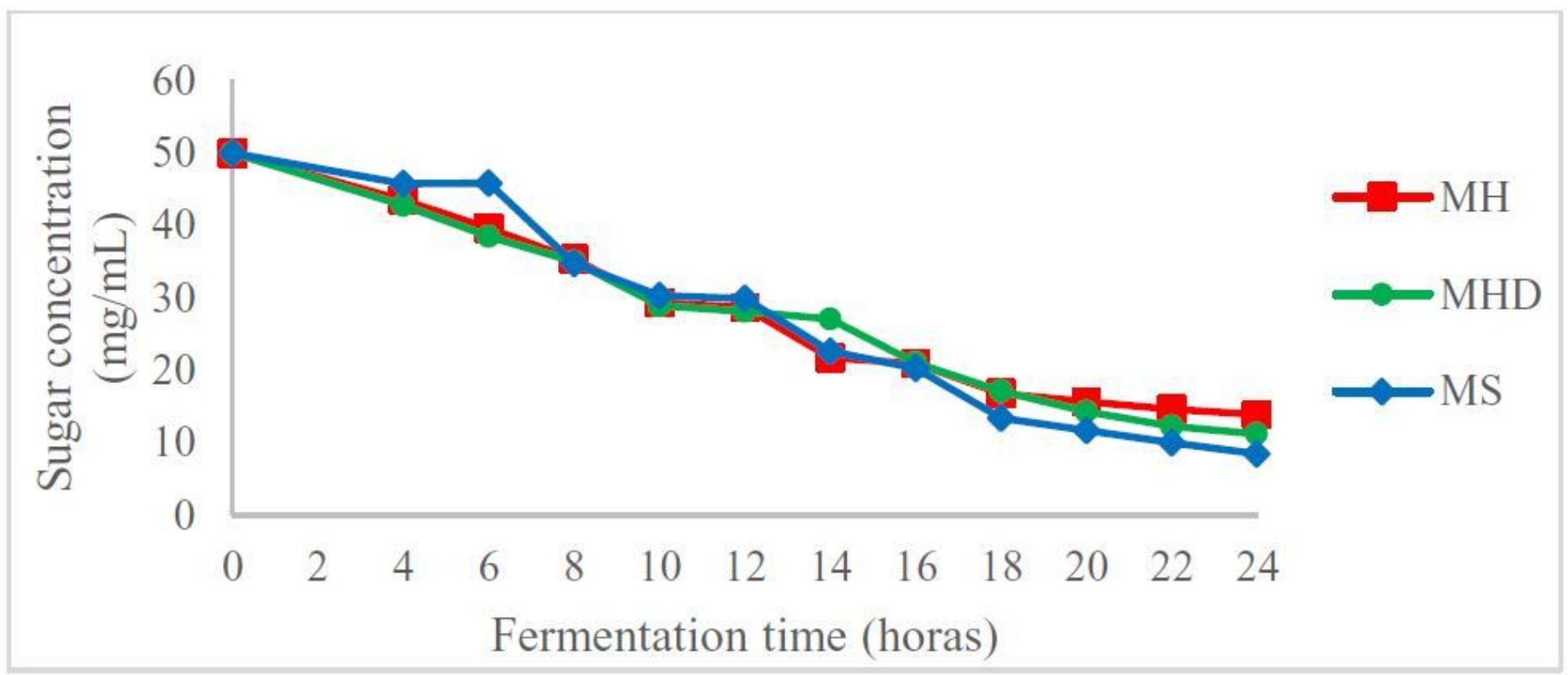

Figure 15

Sugar consumption present in the fermentation media used by the Saccharomyces cerevisiae and Pachysolen tannophilus intercropping during the 24-hour period in the 2-hour interval. 